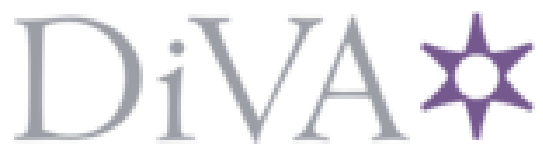

http://www.diva-portal.org

This is the published version of a paper published in The FASEB Journal.

Citation for the original published paper (version of record):

Hoffman, J. (2020)

High shear stress amplitude in combination with prolonged stimulus duration determine induction of osteoclast formation by hematopoietic progenitor cells The FASEB Journal, 34(2): 3755-3772 https://doi.org/10.1096/fj.201901458R

Access to the published version may require subscription.

N.B. When citing this work, cite the original published paper.

Permanent link to this version:

http://urn.kb.se/resolve?urn=urn:nbn:se:kth:diva-299805 


\title{
High shear stress amplitude in combination with prolonged stimulus duration determine induction of osteoclast formation by hematopoietic progenitor cells
}

\author{
Cornelia Bratengeier $^{1}$ | Aneta Liszka ${ }^{1}$ | Johan Hoffman ${ }^{3}$ | Astrid D. Bakker ${ }^{2}$ | \\ Anna Fahlgren ${ }^{1}$
}

${ }^{1}$ Department of Clinical and Experimental Medicine, Division of Cell Biology, Linköping University, Linköping, Sweden ${ }^{2}$ Department of Oral Cell Biology, ACTA-University of Amsterdam and Vrije Universiteit Amsterdam, Amsterdam Movement Sciences, Amsterdam, The Netherlands

${ }^{3}$ Department of Computational Science and Technology, KTH Royal Institute of Technology, Stockholm, Sweden

\section{Correspondence}

Cornelia Bratengeier, Department of Clinical and Experimental Medicine, Division of Cell Biology, Linköping University, Linköping 581 85, Sweden. Email: cornelia.bratengeier@liu.se

Funding information

Vetenskapsrådet (Swedish Research Council Formas), Grant/Award Number: 2016-01822, 2016-06097, 521-20132593; VINNOVA (Swedish Governmental Agency for Innovation Systems), Grant/Award Number: 2012-04409

\begin{abstract}
To date, it is unclear how fluid dynamics stimulate mechanosensory cells to induce an osteoprotective or osteodestructive response. We investigated how murine hematopoietic progenitor cells respond to 2 minutes of dynamic fluid flow stimulation with a precisely controlled sequence of fluid shear stresses. The response was quantified by measuring extracellular adenosine triphosphate (ATP), immunocytochemistry of Piezo1, and sarcoplasmic/endoplasmic $\mathrm{Ca}^{2+}$ reticulum ATPase 2 (SERCA2), and by the ability of soluble factors produced by mechanically stimulated cells to modulate osteoclast differentiation. We rejected our initial hypothesis that peak wall shear stress rate determines the response of hematopoietic progenitor cells to dynamic fluid shear stress, as it had only a minor correlation with the abovementioned parameters. Low stimulus amplitudes corresponded to activation of Piezo1, SERCA2, low concentrations of extracellular ATP, and inhibition of osteoclastogenesis and resorption area, while high amplitudes generally corresponded to osteodestructive responses. At a given amplitude ( $3 \mathrm{~Pa}$ ) and waveform (square), the duration of individual stimuli (duty cycle) showed a strong correlation with the release of ATP and osteoclast number and resorption area. Collectively, our data suggest that hematopoietic progenitor cells respond in a viscoelastic manner to loading, since a combination of high shear stress amplitude and prolonged duty cycle is needed to trigger an osteodestructive response.
\end{abstract}

Plain Language Summary: In case of painful joints or missing teeth, the current intervention is to replace them with an implant to keep a high-quality lifestyle. When exercising or chewing, the cells in the bone around the implant experience mechanical loading. This loading generally supports bone formation to strengthen the bone and prevent breaking, but can also stimulate bone loss when the mechanical loading

\footnotetext{
Abbreviations: ATP, adenosine triphosphate; CTCF, corrected Total Cell Fluorescence; CTX-I, c-terminal telopeptides of type I collagen; Duty cycle (DC), percent of active loading duration per one loading period; HALF, stimulation profile with high amplitude ( $3.0 \pm 0.2 \mathrm{~Pa})$ and low frequency $(1 \mathrm{~Hz})$; LAHF, stimulation profile with low amplitude $(0.7 \pm 0.3 \mathrm{~Pa})$ and high frequency $(5 \mathrm{~Hz})$; LALF, stimulation profile with low amplitude $(0.7 \pm 0.3 \mathrm{~Pa})$ and low frequency $(1 \mathrm{~Hz})$; LDH, lactate dehydrogenase; M-CSF, macrophage colony stimulating factor; PWSSR, peak wall shear stress rate; RANKL, receptor activator of nuclear factor kappa-B ligand/ tumor necrosis factor ligand superfamily member 11 (TNFSF11); SR/ER, sarco/endoplasmic reticulum; TRAP, tartrate-resistant acid phosphatase.
}

Astrid D. Bakker and Anna Fahlgren shared last authors did equally amount of work. 
becomes too high around orthopedic and dental implants. We still do not fully understand how cells in the bone can distinguish between mechanical loading that strengthens or weakens the bone. We cultured cells derived from the bone marrow in the laboratory to test whether the bone loss response depends on (i) how fast a mechanical load is applied (rate), (ii) how intense the mechanical load is (amplitude), or (iii) how long each individual loading stimulus is applied (duration). We mimicked mechanical loading as it occurs in the body, by applying very precisely controlled flow of fluid over the cells. We found that a mechanosensitive receptor Piezol was activated by a low amplitude stimulus, which usually strengthens the bone. The potential inhibitor of Piezo1, namely SERCA2, was only activated by a low amplitude stimulus. This happened regardless of the rate of application. At a constant high amplitude, a longer duration of the stimulus enhanced the bone-weakening response. Based on these results we deduce that a high loading amplitude tends to be bone weakening, and the longer this high amplitude persists, the worse it is for the bone.

\section{K E Y W O R D S}

aseptic loosening, bone marrow, Piezo1, SERCA2, viscoelastic

\section{INTRODUCTION}

Aseptic loosening is a major clinical problem in total joint arthroplasty. Excessive migration of a knee or hip arthroplasty during the first six months after surgery predicts later prosthetic loosening. ${ }^{1}$ Weight-bearing movements by patients with a migrating prosthesis produce pressurized fluid flow at the periprosthetic interface. ${ }^{2}$ Clinical and experimental observations suggest that this fluid pressure and fluid velocity drive mechanical loading-induced bone loss in periprosthetic bone. ${ }^{3,4}$ Loading-induced fluid flow has generally been associated with an increase rather than a decrease of bone mass, ${ }^{5,6}$ so what defines the apparent tipping point where the flow-induced stimulus changes from being osteoanabolic to osteocatabolic? How does fluid flow impact mechanosensitive cells at the molecular level?

At the periprosthetic interface, impact loading quickly causes a thin layer of interstitial fluid to flow at a very high velocity. $^{7}$ In a rat model for pressure-induced periprosthetic osteolysis, a short duration impact loading with a high loading rate induces osteoclast differentiation. ${ }^{8}$ In cultured mouse osteocyte-like cells, loading induces a stronger response if initiated by a strong acceleration of the flow, known as a stress kick. 9,10

We note that fluid mechanical stimulation as the result of impact loads and stress kicks accelerates fluid flow--that is, it enhances the rate of change of the fluid velocity. In cultured mouse osteocyte-like cells, the rate of change of fluid velocity is linearly correlated with the release of nitric oxide and prostaglandins. ${ }^{11}$ This goes along with the findings that low amplitude high frequency loading results in an osteoprotective response and recent studies demonstrate that high amplitude low frequency loading results in an osteodestructive response. ${ }^{12,13}$ These data suggest that the initial rate of change of fluid velocity influences how bone cells respond to mechanical loading, and thus perhaps defines the tipping point between an osteoanabolic and osteo-catabolic mechanical stimulus.

The mechanism through which mechanoresponsive cells, in general, convert mechanical stimuli such as fluid flow into biochemical responses includes a multitude of interconnected mechanosensitive intracellular and extracellular structures, such as stretch-activated ion channels, caveoli, and the actin cytoskeleton. More specifically, a cell subjected to fluid flow experiences pressure and shear stresses acting on the surface of the cell, stretching the cell membrane and redistributing the forces into intracellular structures, most notably the cytoskeleton. The internal forces inside the cytoskeleton and the biomechanical properties of the cell, together determine the precise nature of the cell deformation. If a cell responds immediately to an applied force by exhibiting a local stretch proportional to the local stress and returns to its original shape when the force ceases-like a spring - the deformation is elastic; if a cell responds after a prolonged duration of the applied force, the deformation is viscoelastic; and if a cell responds with a deformation that is nonreversible, the deformation is plastic. Astrocytes, for example, respond in a viscoelastic manner to fluid shear stress applied with a high rate of 
change of the fluid velocity. At this high rate of change of the fluid velocity, the astrocytes showed sharp gradients in cytoskeletal tension, leading to a corresponding rapid increase in intracellular calcium levels. When the rate of change of the fluid velocity was slower, the cells deformed more uniformly and the calcium influx was a lot slower as well, suggesting that fluid dynamics determine viscoelastic behavior of certain cell types, and perhaps also the type of mechanosensitive molecular complexes that are activated. ${ }^{14}$ Plasticity and viscoelastic behavior of cells profoundly affect the activation of the evolutionary-conserved Piezo proteins. ${ }^{15}$ Piezo1 channels are located in the membrane bilayer and respond shear stress-induced membrane stretch within milliseconds after mechanical loading, independent of the cytoskeleton, leading to the release of adenosine triphosphate (ATP) in the extracellular environment. ${ }^{16-18} \mathrm{~A}$ recent study found that co-localization of sarcoplasmic/endoplasmic $\mathrm{Ca}^{2+}$ reticulum ATPase 2 (SERCA2) with Piezo1 suppresses mechanosensitivity of Piezo $1 .{ }^{19}$ However, it is unknown how activation of Piezo1 and co-localization of Piezo1with SERCA2 are governed by fluid flow with different dynamic properties, and whether activation of these molecules is related to the stimulation of osteoclast formation.

To understand the biophysical mechanism that induces osteoclast differentiation, we determined the range of fluid flow characteristics (rate, amplitude, and duration) that induce the release of osteoclast-stimulating factors by hematopoietic progenitor cells. Here, we hypothesize that peak shear stress rate drives the production of osteoclast-stimulating or inhibiting factors by cultured hematopoietic progenitors subjected to fluid shear stress.

\section{2 | MATERIAL AND METHODS}

\subsection{Isolation of mouse hematopoietic progenitor cells}

The animal care and use committee of Linköping University Ethical Board approved the use of experimental animals (\#4-15, \#1605). Bone marrow from the long bones of sacrificed male $\mathrm{C} 57 \mathrm{bl} / 6 \mathrm{~J}$ wild-type mice (7-10 weeks) (Janvier Labs, Le Genest-Saint-Isle, France) were isolated. Hematopoietic progenitor cells were generated as previously described. ${ }^{20}$ Briefly, whole bone marrow was incubated for 48 hours on untreated culture dishes in the presence of $100 \mathrm{ng} / \mathrm{mL}$ recombinant mouse macrophage colony stimulating factor (M-CSF) protein (R\&D Systems, Inc., Minneapolis, MN, USA). After 48 hours, the cells were harvested using a $0.02 \%$ EDTA solution (Sigma-Aldrich Sweden, Stockholm, Sweden) and seeded at $1.0 \times 10^{5}$ cells $/ \mathrm{cm}^{2}$ onto $5 \mu \mathrm{g} / \mathrm{cm}^{2}$ fibronectin-coated glass slides (Sigma-Aldrich Sweden) for 24 hours before mechanical stimulation. Hematopoietic progenitor cell cultures were obtained from separate mice and analyzed separately ( $n=6$, separate experiments).

\subsection{Application of pulsating fluid flow}

Murine hematopoietic progenitor cells were subjected to 2 or 60 minutes of pulsating fluid flow using a parallel-plate flow chamber as previously described. ${ }^{12,13}$ MEM $\alpha$ (Life Technologies Europe, Stockholm, Sweden) supplemented with 1\%PSF (Life Technologies Europe) was used as a fluid flow medium. The conditioned medium was stored for further experiments.

Adaptations of the loading profiles were performed using LabVIEW Professional Development System (V 15.0F2, National Instruments Corporation, Austin, TX, USA) based on previous studies ${ }^{12,13,21}$ (Figures 1 and S1). To rapidly and smoothly increase (or decrease) the control signal to the pump, we implemented a waveform using the error function (erf) as defined in (1). We introduced the adjustable scaling parameter tau $(t-0)$, which determines how "sharply" the transition from the low to the high value occurs between 0 and $t$. The waveform was completed by implementing the same function with $T-t$, where $T$ is the time of the midpoint of the desired fall in the signal:

$$
\operatorname{erf}(x)=\frac{2}{\sqrt{\pi}} \times \int_{0}^{t} e^{-t^{2}} d t
$$

Using the volume flow rate in the flow chamber, we estimated the shear stresses experienced by the cells placed on the bottom wall of the chamber. The peak wall shear stress rate $[\mathrm{Pa} / \mathrm{s}]$, plateau stimulation duration $[\mathrm{s}]$, and plateau wall shear stress $[\mathrm{Pa}]$ were estimated from a volume flow rate determined as the average of the recording at the inlet and outlet of the parallel flow chamber with a ME3PXN320 inline flow sensors (Transonic Europe B.V., Elsloo, Netherlands). The pulsatile volume flow rate was recorded using a TS410 Tubing Flow Module (Transonic Europe) with a $0.1 \mathrm{~Hz}$ Filter at a 1/4 flow scale. Recording of the flow profiles was repeated three times for 30 seconds each time $(n=3)$.

The wall shear stress at the peak or at the plateau was estimated using formula (2) within one loading cycle, repeated on six random loading cycles recorded before and after the parallel flow chamber, where $Q=$ volume flow rate $\left[\mathrm{m}^{3} / \mathrm{s}\right]$, $\mu=$ dynamic viscosity [Pa s], $b=$ channel width [m], and $h=$ channel height $[\mathrm{m}]$ :

$$
\tau_{\text {PEAK or PLAT }}=\frac{6 \times Q \times \mu}{b \times h^{2}} .
$$




\begin{tabular}{|c|c|c|c|c|c|c|c|}
\hline $\begin{array}{l}\text { Clinical } \\
\text { Relevance }\end{array}$ & Identification & Flow Profile & $\begin{array}{l}\text { Loading } \\
\text { Amplitude [Pa] }\end{array}$ & $\begin{array}{l}\text { Peak wall shear } \\
\text { stress rate }[\mathrm{Pa} / \mathrm{s}]\end{array}$ & $\begin{array}{l}\text { Plateau } \\
\text { Duration [s] }\end{array}$ & $\begin{array}{l}\text { Plateau Wall } \\
\text { shear stress [Pa] }\end{array}$ & $\begin{array}{l}\text { Area under } \\
\text { Curve }\left[\mathrm{Pa}^{*} \mathrm{~s}\right]\end{array}$ \\
\hline $\begin{array}{l}\text { Stress } \\
\text { Shielding }\end{array}$ & Unloading & $\begin{array}{lll} & \\
& \\
0\end{array}$ & $0.0 \pm 0.0$ & $\begin{array}{l}0.0 \pm \\
0.0\end{array}$ & $\begin{array}{l}0.0 \pm \\
0.0\end{array}$ & $\begin{array}{l}0.0 \pm \\
0.0\end{array}$ & $\begin{array}{l}0.0 \pm \\
0.0\end{array}$ \\
\hline \multirow[t]{3}{*}{$\begin{array}{l}\text { Physiological } \\
\text { Loading }\end{array}$} & Sine-LAHF & 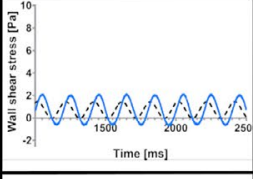 & $0.7 \pm 0.3$ & $\begin{array}{l}20.6 \pm \\
4.9\end{array}$ & $\begin{array}{l}0.0 \pm \\
0.0\end{array}$ & $\begin{array}{l}0.0 \pm \\
0.0\end{array}$ & $\begin{array}{l}0.0 \pm \\
0.0\end{array}$ \\
\hline & $\begin{array}{l}\text { Square-LALF } \\
50 \%\end{array}$ & 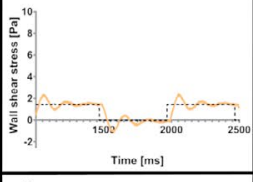 & $0.7 \pm 0.3$ & $\begin{array}{l}47.5 \pm \\
11.7\end{array}$ & $\begin{array}{l}0.420 \pm \\
0.002\end{array}$ & $\begin{array}{l}1.48 \pm \\
0.010\end{array}$ & $\begin{array}{l}0.620 \pm \\
0.001\end{array}$ \\
\hline & $\begin{array}{l}\text { Error-LALF } \\
50 \%\end{array}$ & 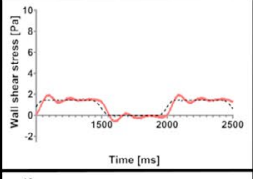 & $0.7 \pm 0.3$ & $\begin{array}{l}25.4 \pm \\
4.4\end{array}$ & $\begin{array}{l}0.412 \pm \\
0.004\end{array}$ & $\begin{array}{l}1.47 \pm \\
0.005\end{array}$ & $\begin{array}{l}0.620 \pm \\
0.005\end{array}$ \\
\hline \multirow[t]{5}{*}{ Kick-Stress } & $\begin{array}{l}\text { Square-HALF } \\
6 \%\end{array}$ & 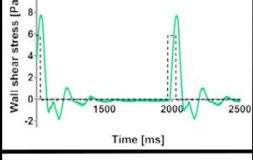 & $3.0 \pm 0.2$ & $\begin{array}{l}185.3 \pm \\
47.2\end{array}$ & $\begin{array}{l}0.0 \pm \\
0.0\end{array}$ & $\begin{array}{l}0.0 \pm \\
0.0\end{array}$ & $\begin{array}{l}0.0 \pm \\
0.0\end{array}$ \\
\hline & $\begin{array}{l}\text { Square-HALF } \\
14 \%\end{array}$ & 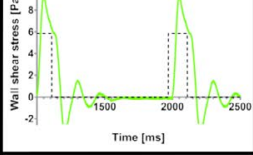 & $3.0 \pm 0.2$ & $\begin{array}{l}189.0 \pm \\
44.1\end{array}$ & $\begin{array}{l}0.065 \pm \\
0.003\end{array}$ & $\begin{array}{l}5.93 \pm \\
0.136\end{array}$ & $\begin{array}{l}0.357 \pm \\
0.040\end{array}$ \\
\hline & $\begin{array}{l}\text { Square-HALF } \\
22 \%\end{array}$ & 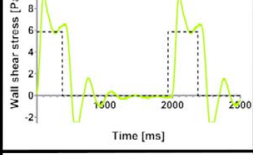 & $3.0 \pm 0.2$ & $\begin{array}{l}188.0 \pm \\
43.3\end{array}$ & $\begin{array}{l}0.151 \pm \\
0.015\end{array}$ & $\begin{array}{l}5.40 \pm \\
0.872\end{array}$ & $\begin{array}{l}0.793 \pm \\
0.033\end{array}$ \\
\hline & $\begin{array}{l}\text { Square-HALF } \\
36 \%\end{array}$ & 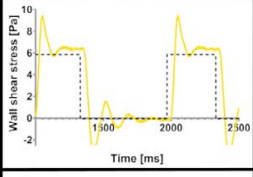 & $3.0 \pm 0.2$ & $\begin{array}{l}188.0 \pm \\
42.6\end{array}$ & $\begin{array}{l}0.265 \pm \\
0.015\end{array}$ & $\begin{array}{l}5.63 \pm \\
0.356\end{array}$ & $\begin{array}{l}1.410 \pm \\
0.113\end{array}$ \\
\hline & $\begin{array}{l}\text { Error-HALF } \\
50 \%\end{array}$ & 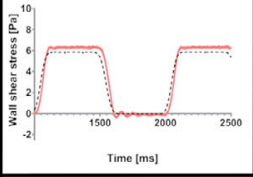 & $3.0 \pm 0.2$ & $\begin{array}{l}78.5 \pm \\
2.3\end{array}$ & $\begin{array}{l}0.384 \pm \\
0.004\end{array}$ & $\begin{array}{l}6.42 \pm \\
0.178\end{array}$ & $\begin{array}{l}2.453 \pm \\
0.040\end{array}$ \\
\hline $\begin{array}{l}\text { Supra- } \\
\text { physiological } \\
\text { Loading }\end{array}$ & $\begin{array}{l}\text { Square-HALF } \\
50 \%\end{array}$ & (20) & $3.0 \pm 0.2$ & $\begin{array}{l}177.1 \pm \\
50.8\end{array}$ & $\begin{array}{l}0.423 \pm \\
0.004\end{array}$ & $\begin{array}{l}6.18 \pm \\
0.009\end{array}$ & $\begin{array}{l}2.607 \pm \\
0.005\end{array}$ \\
\hline
\end{tabular}

F I G U RE 1 Estimated fluid flow-induced stimuli experienced by cells estimated from the average of recordings before and after the parallel fluid flow chamber. The peak wall shear stress rate $[\mathrm{Pa} / \mathrm{s}]$, plateau duration $[\mathrm{s}]$, and plateau wall shear stress $[\mathrm{Pa}]$ were estimated from a volume flow rate determined as the average of the recording at the inlet and outlet of the parallel flow chamber with a ME3PXN320 inline flow sensors. The approximate area under the curve $(\mathrm{AuC})[\mathrm{Pa} \times \mathrm{s}]$ was estimated as the product formed by plateau wall shear stress and plateau duration. $\mathrm{n}=3$, separate records

The peak wall shear stress rate $\left(\tau_{\mathrm{PWSSR}}\right)$ (ie, the initial rate of change of the wall shear stress or kick stress) was estimated using formula (3) within one loading cycle, repeated on six random loading cycles recorded before and after the parallel flow chamber, where $\tau_{\mathrm{PEAK}}=$ average of the top $5 \%$ of the positive peak values recorded by the flow meter, 
$\tau_{0}=$ average of recorded values in which no signal was applied,

$t_{\text {PEAK }}=$ time point where the peak amplitude was highest , and $t_{0}=$ time point where the positive signal was initiated:

$$
\tau_{\mathrm{PWSSR}}=\frac{\left(\tau_{\mathrm{PEAK}}-\tau_{0}\right)}{\left(t_{\mathrm{PEAK}}-t_{0}\right)}
$$

The approximate area under the curve $\left(\mathrm{AUC}_{\mathrm{SQUARE} / \mathrm{ERF}}\right)^{22}$ was defined per duty cycle for stimuli with a plateau shear stress for square or erf as a surrogate for stimulus intensity using formula (4), where $\tau_{\mathrm{PLAT}}=$ average of the values at the constant level after the resonance of the initial peak and $t_{\text {PLAT }}=$ duration where a constant positive amplitude was measured:

$$
\mathrm{AUC}_{\mathrm{SQUARE} / \mathrm{ERF}}=\tau_{\mathrm{PLAT}} \times t_{\mathrm{PLAT}} .
$$

\subsection{Osteoclast differentiation assay}

Briefly, pooled whole bone marrow of two male C57bl/6J wild-type mice (8-10 weeks; Janvier Labs) were cultured in a mixture of $50 \%$ freshly prepared medium and $50 \%$ of condition medium. Each well, including the positive control, contained $30 \mathrm{ng} / \mathrm{mL}$ recombinant murine $\mathrm{M}-\mathrm{CSF}$ (R\&D Systems, Inc.) and $20 \mathrm{ng} / \mathrm{mL}$ recombinant murine receptor activator of nuclear factor kappa- $\beta$ ligand/ tumor necrosis factor ligand (RANKL) (R\&D Systems, Inc.). ${ }^{20}$ RANKL was omitted in the negative control. After 6 days of culture, cells were fixed with $4 \%$ formaldehyde and stained with a tartrate-resistant acid phosphatase (TRACP) kit according to the manufacturer's instructions (SigmaAldrich Sweden). Nuclei were stained with DAPI (Life Technologies Europe). The TRAP-positive multinucleated cells ( $\geq 3$ nuclei/cell) were counted manually. The conditioned medium after 2 minutes or 60 minutes of mechanical loading was analyzed separately $(n=6$, separate experiments).

\subsection{Bone resorption assay}

Bone marrow pooled from three male C57bl/6J wild-type mice (7-12 weeks; Janvier Labs) were cultured in the presence of $100 \mathrm{ng} / \mathrm{ml}$ recombinant mouse M-CSF protein (R\&D Systems) for 72 hours, after which the adherent cells were seeded at a density of $1.5 \times 10^{4}$ cells per $4 \times 4 \times 0.2 \mathrm{~mm}$ bovine bone slices. Cells were cultured in a mixture of $50 \%$ fresh medium and $50 \%$ of condition medium for 14 days. Each well, contained $50 \mathrm{ng} / \mathrm{mL}$ recombinant murine M-CSF (R\&D Systems, Inc.) and $10 \mathrm{ng} / \mathrm{mL}$ recombinant murine RANKL (R\&D Systems, Inc.). RANKL was omitted in the negative control. After 14 days of culture, the medium was collected and c-terminal telopeptides of type I collagen (CTX-I) was quantified in the CrossLaps for Culture (CTX-I) ELISA (\#AC-07F1, Immunodiagnostic Systems Holdings PLC, United Kingdom) ( $n=6$, separate experiments). Bone slices were sonicated for 30 minutes in $10 \%$ ice-cold $\mathrm{NH}_{4} \mathrm{OH}$ (Sigma-Aldrich Sweden), thoroughly washed and incubated in saturated Alum solution $\left(10 \%, \mathrm{KAl}\left[\mathrm{SO}_{4}\right]^{2} \times 12 \mathrm{H}_{2} \mathrm{O}\right.$, Sigma-Aldrich Sweden) for 10 minutes. Resorption pits were stained with Coomassie Brilliant Blue (PhastGel Blue R, Sigma-Aldrich). Images were taken using an Olympus BX51 bright field microscope (Olympus Europe GmbH, Hamburg, Germany) with an UPlanFI $10 \times / 0.30$ na air objective (Olympus Europe $\mathrm{GmbH}$ ). The $4 \times 4 \mathrm{~mm}$ bone slide was virtually divided into four quarters and region of interest (ROI) was adjusted to the center of each quarter, covering approximately $70 \%$ of each quarter using cellSens Entry software (version 1.8.1 [build 10891], Olympus Europe GmbH). Percent of resorbed area in relation to total area in the selected ROI was quantified using Fiji Image $\mathrm{J}^{23}$ as described in the supplementary data. ( $n=6$, separate experiments).

\subsection{ATP and LDH measurements}

Extracellular ATP was measured using the ATP determination kit (Fisher Scientific Sweden, Göteborg, Sweden) according to the manufacturer's instructions. Extracellular levels of Lactate dehydrogenase (LDH) were measured using the CytoTox96 nonradioactive cytotoxicity assay (Promega Biotech AB, Nacka, Sweden) according to manufacturer's instructions. Snap frozen conditioned medium after 2 minutes of mechanical loading was analyzed separately $(n=6$, separate experiments).

\subsection{Cellular co-detection of Piezo1 and SERCA2}

Immediately after 2 minutes of mechanical loading, hematopoietic progenitor cells were fixed in $4 \%$ formaldehyde (Merck, Stockholm, Sweden). Fixed and permeabilized cells were stained with anti-SERCA2 ATPase monoclonal antibody [2A7-A1] (1:100, Abcam, Cambridge, UK) for 36 hours and subsequently with PIEZO1 polyclonal antibody (1:400, Fisher Scientific Sweden) for 24 hours. Donkey anti-Mouse IgG highly cross-adsorbed secondary antibody (Alexa Fluor Plus 594, 1:200; Fisher Scientific Sweden) and Goat anti-Rabbit IgG highly cross-adsorbed secondary antibody (Alexa Fluor Plus 488, 1:200; Fisher Scientific Sweden) were used for detection. Filamentous actin (F-Actin) was stained with Alexa Fluor Plus 405 
Phalloidin (1:1000, Fisher Scientific Sweden). The stained samples were examined using an inverted Nikon Eclipse Ti microscope with a Plan Apo 100x/1.40 oil DIC H objective (Nikon Instruments Europe B.V., Amsterdam, Netherlands). The exposure time was held constant for each color channel.

To detect cellular levels of Piezo1 and SERCA2, the "look-up-table" (LUT) generated by the negative control staining, where the primary antibodies were omitted, was applied to all images using NIS-Elements imaging software (version 4.50.00 (build 1117) patch03, Nikon Instruments Europe) to correct for unspecifically bound detection antibodies. Each stimulating group included six separate glass slides for analysis, which occurred randomized and blinded. On average, $75 \pm 6$ single cells in approximately 20 randomly taken images per glass slide were analyzed, resulting in $442 \pm 52$ single cells analyzed per treatment. Fiji Image ${ }^{23}$ was used to determine the corrected total cell fluorescence $(\mathrm{CTCF})^{24}$ of Piezo1 and SERCA2 for each treatment and estimated using formula $(5)(n=6$, separate experiments):

$$
\left.\begin{array}{rl}
\mathrm{CTCF}= & \text { IntergratedDensity }_{\text {Cell }} \\
& -\left(\text { Area }_{\text {Cell }} \times\right. \text { MeanIntegratedDensity } \\
\text { Background }
\end{array}\right) .
$$

\section{$2.7 \quad$ Statistics}

This study measures the soluble factors stimulated by mechanical loading that modulate osteoclast formation as the main variable. To evaluate the induction or suppression of osteoclast formation and osteoclast activity via resorption area, we used the ratio of osteoclasts or resorbed areas resulting from the different mechanical loading regimes and osteoclasts or resorbed area in the assay positive control. We used direct measurements for the statistical analysis of extracellular ATP, LDH, CTX-I, and Corrected Total Cell Fluorescence (CTCF) measurements for Piezo1 and SERCA2 and parameter for cellular morphology. SPSS Statistics, version 24.0.0.0 (IBM, New York, NY, USA) was used to determine correlation by linear regression analysis. Biological data (eg, ATP, osteoclast number, and Piezo1) were correlated with the average of the recorded Peak wall shear stress rate $[\mathrm{Pa} / \mathrm{s}]$, Loading amplitude $[\mathrm{Pa}]$, Loading duration [s], or approximate area under the curve $[\mathrm{Pa} \times \mathrm{s}]$. Because unloading is not considered an active mechanical loading profile, it was omitted in all linear regression analyses. GraphPad Prism8 for Windows, version 8.0.1(224) (GraphPad Software, San Diego, CA, USA) was used to generate graphs and to evaluate statistical differences between treatment groups by one-way analysis of variance (ANOVA) with Bonferroni correction. Figures were generated with the GNU Image Manipulation Program (GIMP) for Windows, version 2.10.10 (www.gimp.org/). Data are shown as mean \pm SD. $P<.05$ was considered statistically significant.

\section{3 | RESULTS}

\section{1 | Peak wall shear stress rate is not related to the mechanoresponse in hematopoietic progenitor cells}

We compared the response of hematopoietic progenitor cells to three different peak wall shear stress rates: (i) a sine wave (Sine-LAHF) with a low peak wall shear stress rate $(\sim 20 \mathrm{~Pa} / \mathrm{s})$; (ii) two square waves (Square-HALF 6\% and Square-HALF $50 \%)$ with a high peak wall shear stress rate $(\sim 180 \mathrm{~Pa} / \mathrm{s})$; and (iii) unloaded cells, which did not experience any peak wall shear stress rate $(0 \mathrm{~Pa} / \mathrm{s})$ (Figure $2 \mathrm{~A})$.

After applying mechanical loading, we confirmed that hematopoietic progenitor cells remained attached to the fibronectin-coated glass slide and that these cells did not exhibit loading-induced morphological changes of the cell area, cell perimeter, and cell feret's diameter (Figure S2A-C).

Piezo1, a mechanoreceptor that reacts to mechanical loading within milliseconds, was detected after 2 minutes of mechanical loading in all treatment groups. A low peak wall shear stress rate (Sine-LAHF) increased levels of Piezo1 (CTCF of $70.633 \pm 18.202$ ), compared to both stimuli with a high peak wall shear stress rate (Square-HALF 6\%, 4.0-fold and SquareHALF 50\%, 1.8-fold) and no peak shear stress rate (unloading, 5.8-fold). High peak wall shear stress rate (Square-HALF 6\% and Square-HALF 50\%) did not significantly increase levels of Piezo1 compared to no peak shear stress rate (Figure 2B,C). A linear regression analysis revealed a very moderate negative linear correlation (Pearson $R^{2}=0.31$ ) between peak wall shear stress rate $[\mathrm{Pa} / \mathrm{s}]$ and the CTCF of Piezo1 (Figure 2D).

ATP is released into the extracellular environment by hematopoietic progenitor cells in response to mechanical stimulation. Compared to no peak shear stress rate, the regimes with a high peak wall shear stress rate (Square-HALF 6\% and Square-HALF 50\%, 180 Pa/s) stimulated ATP release by 3.4-fold and 9.8-fold, respectively, but Sine-LAHF did not. One mechanical stimulus with a high peak wall shear stress rate (Square-HALF 50\%, 180 Pa/s) also enhanced the release of extracellular ATP compared to Sine-LAHF by 4.8-fold (Figure 2E). A linear regression analysis revealed a moderate positive linear correlation (Pearson $R^{2}=0.47$ ) between peak wall shear stress rate $[\mathrm{Pa} / \mathrm{s}]$ and the release of extracellular ATP [nM] (Figure 2F). To ensure that the extracellular ATP was loading-induced and not due to rupture of cell membranes, we determined the level of extracellular $\mathrm{LDH}$, verifying that none of the mechanical loading regimes tested impaired cell membrane integrity (Figure S2D).

Osteoclast-modulating factors are released by hematopoietic progenitor cells as a result of mechanical stimulation. After 60 minutes of mechanical loading, a low peak wall shear stress rate of $\sim 20 \mathrm{~Pa} / \mathrm{s}$ (Sine-LAHF) reduced the 
formation of osteoclasts by 0.5 -fold compared to the osteoclast assay positive control (\#OC $65 \pm 5$ ). No peak wall shear stress rate (Unloading) had a tendency to increase osteoclast formation (1.2-fold, $P=.0507)$, whereas a high peak wall shear stress rate of $\sim 180 \mathrm{~Pa} / \mathrm{s}$ (Square-HALF 50\%) increased the formation of osteoclasts by 1.3-fold. In contrast, the other stimulation with a high peak wall shear stress rate of $\sim 180$ $\mathrm{Pa} / \mathrm{s}$ (Square-HALF 6\%) did not change osteoclast formation (Figure $2 \mathrm{H}$ ). After only 2 minutes of mechanical loading, a similar modulation of osteoclast formation was observed.
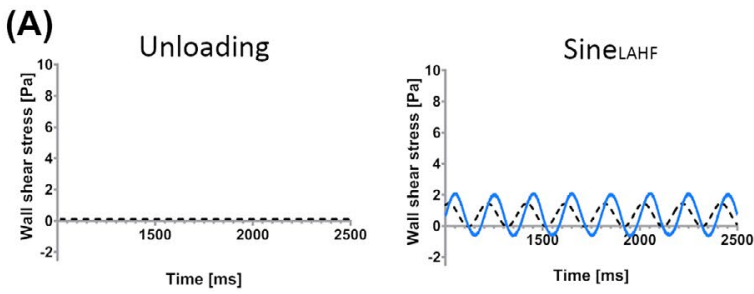

(B)

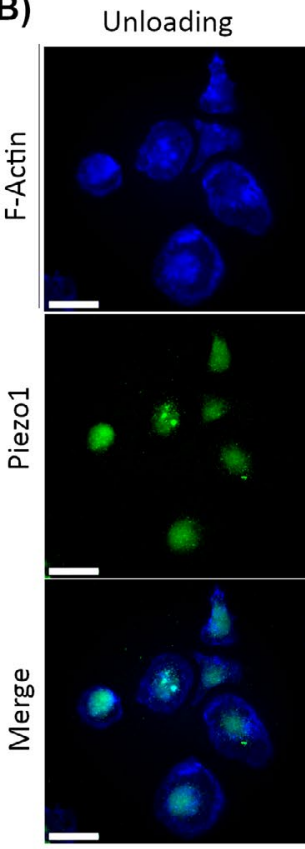

(E)

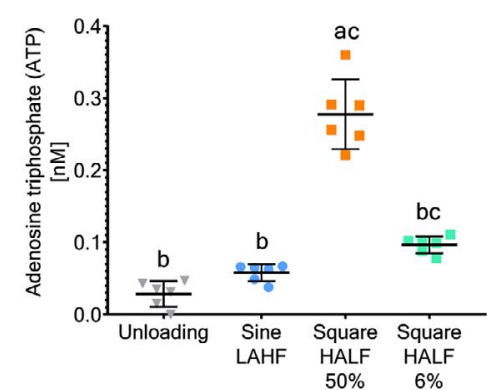

(G)

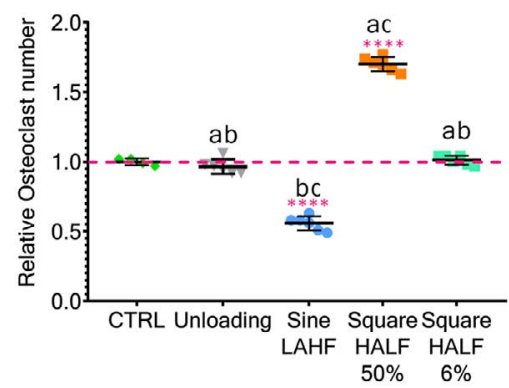

SineLAHF

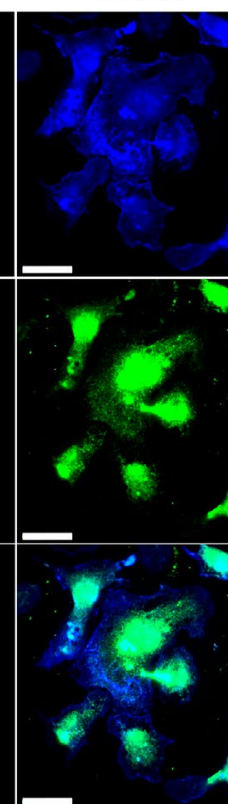

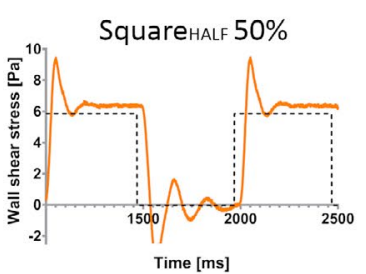

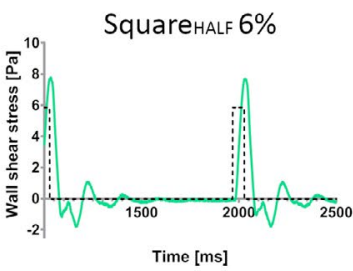

(C)

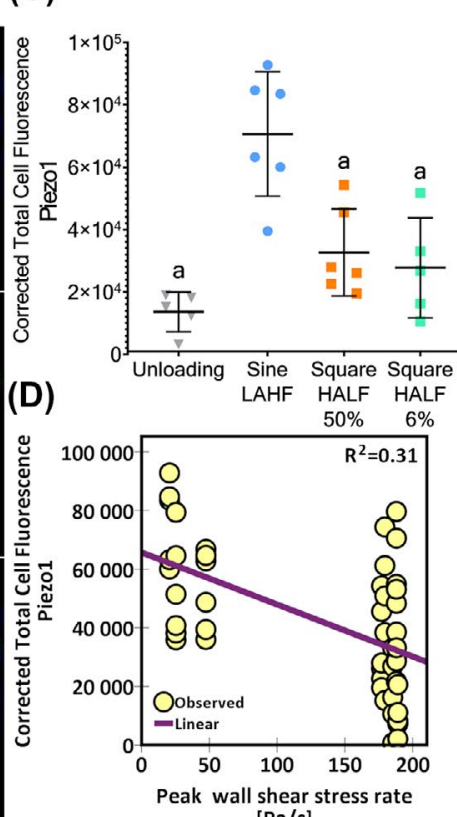

$[\mathrm{Pa} / \mathrm{s}]$
(F)

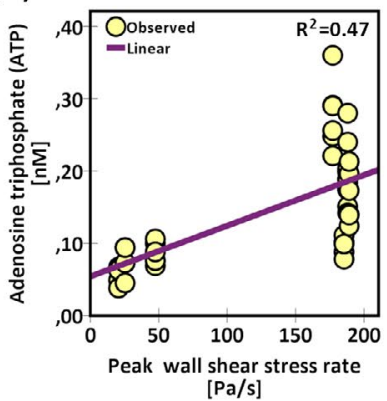

(H)

(I)

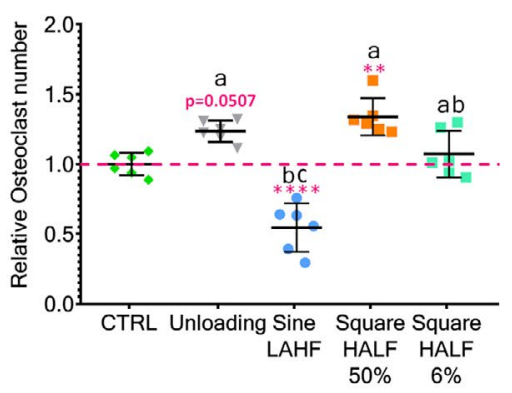


F I G U RE 2 Peak wall shear stress rate does not explain changes in the detection of the mechanoreceptor Piezo1, the release of extracellular ATP, or changes in osteoclast formation. Loading profiles with a variation in peak wall shear stress rate [A] were applied for 2 minutes on hematopoietic progenitor cells. Higher levels of the mechanoreceptor Piezo1 were detected in cells exposed to low peak wall shear stress rate (Sine-LAHF) compared to cells exposed to high peak wall shear stress rate (Square-HALF 6\% and 50\%) or unloaded cells [B, C]. Correlation analysis between peak wall shear stress rate $[\mathrm{Pa} / \mathrm{s}]$ and Piezol fluorescence intensity [CTCF] gives a moderate negative linear relationship [D]. The concentration of extracellular ATP was highest in cells exposed to high peak wall shear stress rate (Square-HAHF 50\%) compared to the other loading profiles $[\mathrm{E}]$. Correlation analysis between peak wall shear stress rate $[\mathrm{Pa} / \mathrm{s}]$ and extracellular ATP $[\mathrm{nM}]$ gives a moderate positive linear relationship [F]. Changes in osteoclast formation after 2 minutes $[\mathrm{G}]$ and 60 minutes $[\mathrm{H}]$ were similar-increased in high peak wall shear stress rate (Square-HAHF 50\%) and decreased in low peak wall shear stress rate (Sine-LAHF). [I] Correlation analysis between peak wall shear stress rate $[\mathrm{Pa} / \mathrm{s}]$ and number of TRAP-positive multinucleated osteoclasts gives a moderate positive linear relationship. In the correlation analysis (1D, F, and I) data obtained at additional shear stress rates, with regimes not displayed in figure $2 \mathrm{~A}$, have been included. a = statistical significance to SineLAHF; $b=$ statistical significance to Square-HALF 50\%; $c=$ statistical significance to Unloading. Pink $*$ statistical significance to osteoclast assay positive control (CTRL), $* * P<.01, * * * * P<.001$, one-way analysis of variance with Bonferroni post hoc test. $\mathrm{n}=6$, separate experiments. Scale bars: $25 \mu \mathrm{m}$

A low peak wall shear stress rate of $\sim 20 \mathrm{~Pa} / \mathrm{s}$ (Sine-LAHF) reduced the formation of osteoclasts by 0.6 -fold compared to the osteoclast assay positive control (\#OC 116.7.2 \pm 2.3 ), whereas a high peak wall shear stress rate of $\sim 180 \mathrm{~Pa} / \mathrm{s}$ (Square-HALF 50\%) increased the formation of osteoclasts by 1.7 -fold. Neither the other stimulation with a high peak wall shear stress rate of $\sim 180 \mathrm{~Pa} / \mathrm{s}$ (Square-HALF 6\%) nor unloading affected the modulation of osteoclast formation by hematopoietic progenitor cells (Figure 2G). A linear regression analysis revealed a moderate positive linear correlation (Pearson $R^{2}=0.34$ ) between peak wall shear stress rate $[\mathrm{Pa} / \mathrm{s}]$ and number of TRAP-positive multinucleated osteoclasts (Figure 2I).

\section{2 | Amplitude and active loading duration per cycle are related to a stronger osteoclast- inducing response}

We rejected our initial hypothesis that peak shear stress rate drives the production of osteoclast-stimulating or inhibiting factors by cultured hematopoietic progenitors because we found that the peak wall shear stress rate played a minor role in the mechanoresponse of hematopoietic progenitor cells. Therefore, we formulated a new hypothesis: loading amplitude and/or active loading duration per cycle play a major role in the release of extracellular ATP and osteoclastinducing soluble factors.

First, we evaluated the effect of loading amplitude alone. A high average loading amplitude of $\sim 3 \mathrm{~Pa}$ (Square-HALF $50 \%$ ) released 3.2-fold more extracellular ATP than a low average loading amplitude of $\sim 0.7 \mathrm{~Pa}$ (Square-LALF $50 \%$ ). An alternative waveform with a similar high average loading amplitude of $\sim 3 \mathrm{~Pa}$, but a lower shear stress rate (Error-HALF $50 \%$ ) released only 1.7-fold more extracellular ATP than a low average loading amplitude of $\sim 0.7 \mathrm{~Pa}$ (Error-LALF $50 \%$ ) (Figure 3A,B). A linear regression analysis was performed to examine the relationship between loading amplitude $[\mathrm{Pa}]$ and the release of extracellular ATP [nM], which resulted in a positive linear correlation (Pearson $R^{2}=0.55$ ) (Figure 3C). In terms of osteoclast modulation, both regimes with a low average loading amplitude of $\sim 0.7 \mathrm{~Pa}$ (Square-LALF $50 \%$, 0.8-fold and Error-LALF 50\%, 0.8-fold) reduced the amount of osteoclast differentiation compared to the osteoclast assay positive control, regardless of their difference in shear stress rate. In contrast, both regimes with a high average loading amplitude of $\sim 3 \mathrm{~Pa}$ (Square-HALF 50\%, 1.7-fold and ErrorHALF $50 \%$, 1.6-fold) increased the amount of osteoclast differentiation (Figure 3A,D). As a result, a linear regression analysis revealed a very strong positive linear correlation (Pearson $R^{2}=0.94$ ) between loading amplitude [Pa] and the number of TRAP-positive multinucleated osteoclasts (Figure 3E). Taken together, we observed that at a similar length of the loading duration per cycle, loading amplitude determines the directionality of the effect on osteoclastogenesis. In Sine-LALF and Sine-HALF, a very similar modulation of osteoclast formation was observed, depending on loading amplitude (Figure S3).

Next, we evaluated the effect of active loading duration per cycle in the high amplitude square loading profiles $(\sim 3 \mathrm{~Pa})$. The longer the active loading per cycle (Figure $3 \mathrm{~F}$ ), the more extracellular ATP was released by the loaded hematopoietic progenitor cells compared to the unloaded cells: $6 \%$ (3.40-fold), 14\% (5.78-fold), 22\% (6.41-fold), $36 \%$ (7.24-fold), and 50\% (9.77-fold). Unloaded hematopoietic progenitor cells released much lower extracellular $\operatorname{ATP}(0.03 \pm 0.02$; Figure $3 \mathrm{G})$. A linear regression analysis revealed a strong positive linear correlation (Pearson $R^{2}=$ 0.72 ) between the length of the loading duration per cycle [s] and the release of extracellular ATP [nM] (Figure 3H) if the shear stress rate and amplitude were kept constant. In addition, the longer the active loading duration per cycle (Figure 3F), the greater the osteoclast formation compared to the osteoclast assay positive control (\#OC 117.8土7.8): $22 \%$ (1.24-fold), 36\% (1.37-fold), and 50\% (1.70-fold). Unloaded cells, as well as short active loading duration per cycle 
(A)

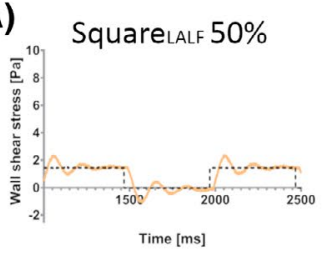

Squarehalf $50 \%$
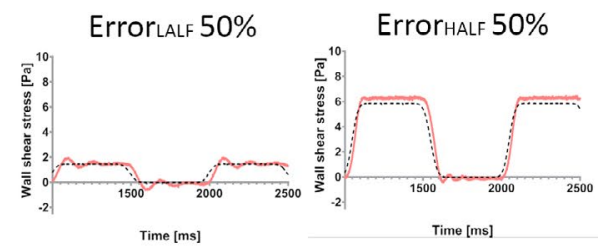

(B)

(C)

(D)

(E)
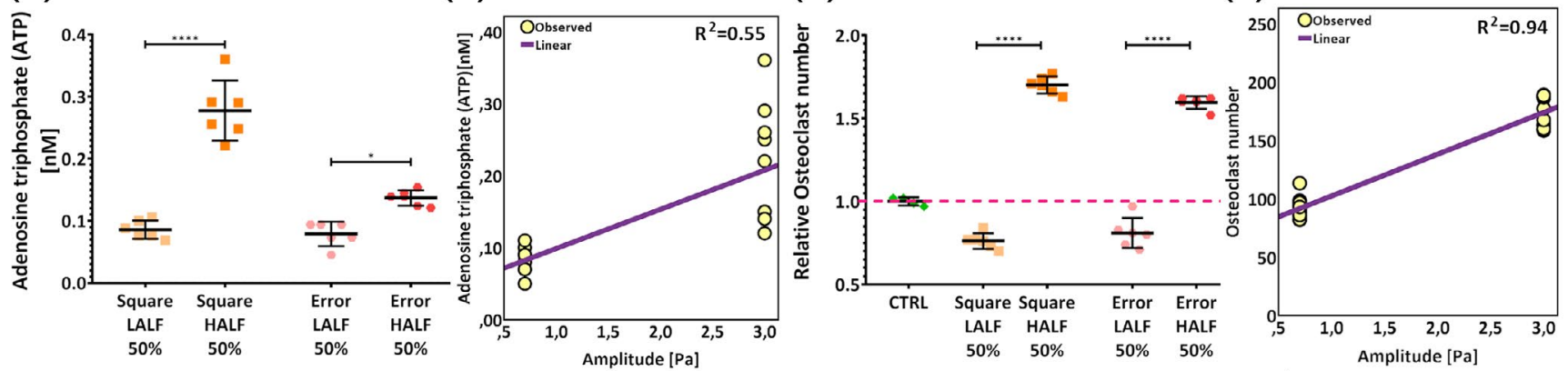

(F)
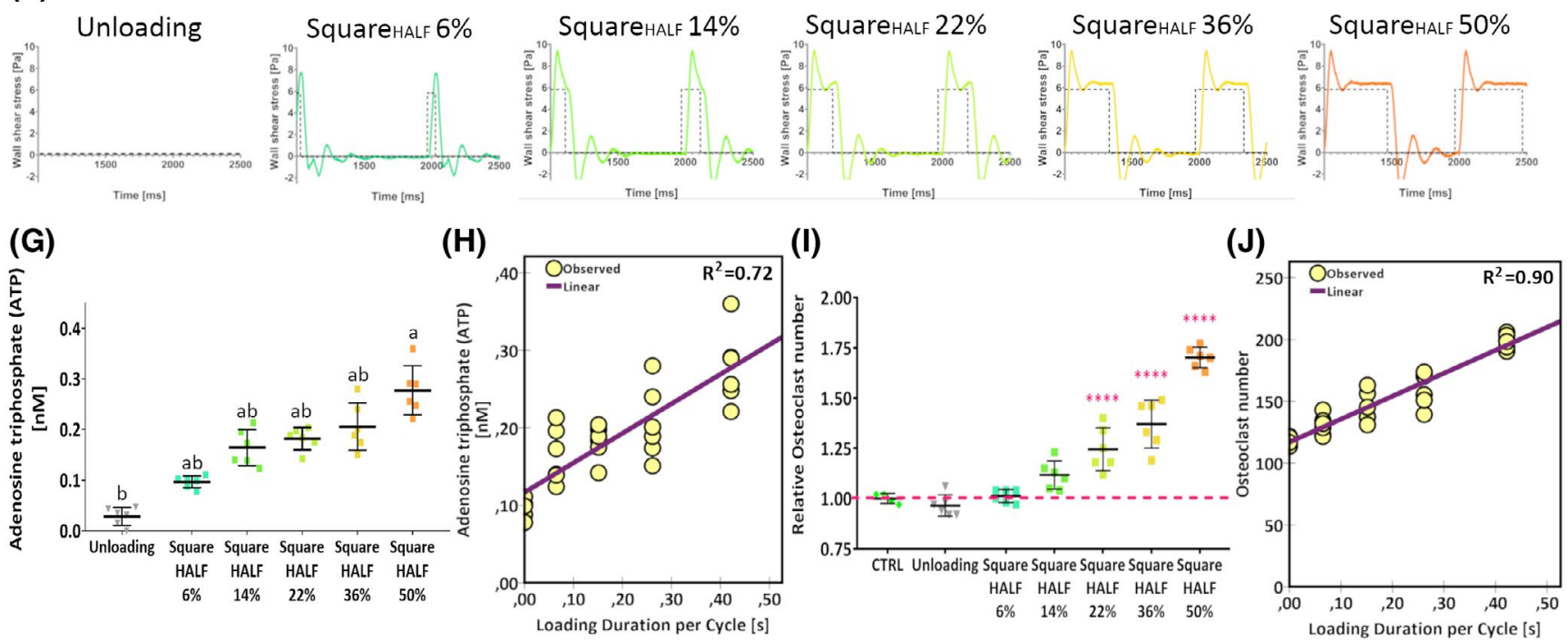

F I G U R E 3 Loading Amplitude and loading duration per cycle explain changes in extracellular ATP and induction of osteoclast formation. Loading profiles with a variation in loading amplitude [A] were applied for 2 minutes on hematopoietic progenitor cells. The concentration of extracellular ATP [B] and formation of osteoclast [D] was higher in loading profiles with high amplitude (Square-HALF 50\% and Error-HALF 50\%) compared to loading profiles with low amplitude (Square-LALF 50\% and Error-LALF 50\%). Correlation analysis between loading amplitude $[\mathrm{Pa} / \mathrm{s}]$ and extracellular ATP gives a moderate positive linear relationship [C], and the number of TRAP-positive multinucleated osteoclasts gives a strong positive linear relationship [E]. Loading profiles with a variation in loading duration per cycle [F] were applied for 2 minutes on hematopoietic progenitor cells. The concentration of extracellular ATP [G] and formation of osteoclast [I] was higher in loading profiles with a longer loading duration per cycle (Square-HALF 22\%-50\%). Correlation analysis between loading duration and extracellular ATP gives a strong positive linear relationship $[\mathrm{H}]$, and the number of TRAP-positive multinucleated osteoclasts gives a strong positive linear relationship [J]. $\mathrm{a}=$ statistical significance to Unloading, $\mathrm{b}=$ statistical significance to Square-HALF 50\%, Pink $*$ = statistical significance to osteoclast assay positive control (CTRL), ${ }^{*} P<.05, * * P<.01$, and $* * * * P<.001$, one-way analysis of variance with Bonferroni post hoc test. $\mathrm{n}=6$, separate experiments

(6\% and $14 \%)$, did not change osteoclast differentiation compared to the osteoclast assay positive control (Figure 3I). Linear regression analysis revealed a strong positive linear correlation (Pearson $R^{2}=0.90$ ) between the length of the loading duration per cycle $[\mathrm{s}]$ and number of TRAP-positive multinucleated osteoclasts at a given loading amplitude and rate (Figure 3J).

\section{3 | The combination of loading amplitude and duration is related to the mechanoresponse in hematopoietic progenitor cells}

Loading duration per cycle at a constant amplitude, as well as loading amplitude at a constant duration strongly correlated 

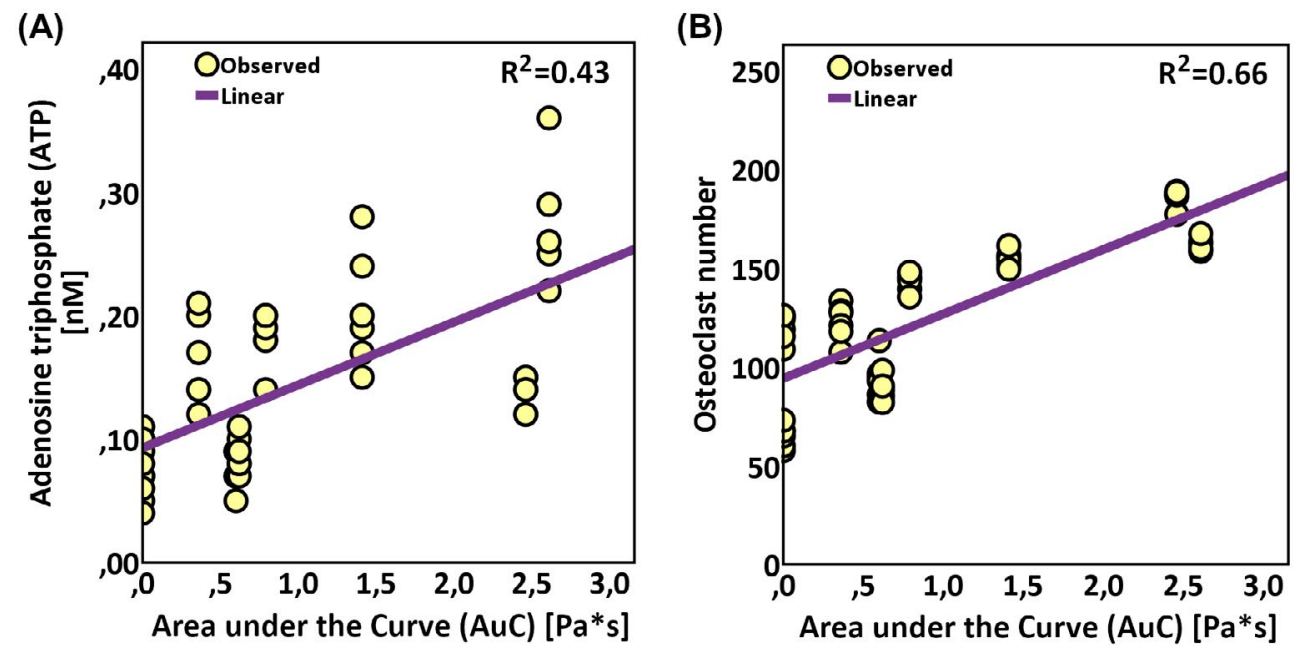

F I G U RE 4 The combination of loading amplitude and duration strongly correlates with osteoclast formation. Correlation analysis between approximate area under the curve $[\mathrm{Pa} * \mathrm{~s}]$ and extracellular ATP gives a moderate positive linear relationship [A]. Correlation analysis between approximate area under the curve $[\mathrm{Pa} \times \mathrm{s}$ ] and TRAP-positive multinucleated osteoclasts gives a strong positive linear relationship [B]. $\mathrm{n}=6$, separate experiments

with the release of extracellular ATP and induction of osteoclast formation. However, we observed that Square-HALF 50\% increased the release of extracellular ATP and increased osteoclast formation, while Square-HALF 6\% did not, suggesting that it is the combination of a higher amplitude with a longer active loading duration that promotes an osteo-catabolic response. Together, duration and amplitude could be a compound parameter for stimulus intensity. Therefore, we further investigated the role of the combination of both factors, loading amplitude and length of loading duration per cycle for the square and error functions, where we could most easily approximate the area under the curve during the plateau phase of the stimuli (Figures 1 and S1). We included data from square and error functions in a wide range of shear stress rates $(\sim 20 \mathrm{~Pa} / \mathrm{s}$ up to $\sim 180 \mathrm{~Pa} / \mathrm{s}$ ), durations (0.06s up to $0.42 \mathrm{~s})$, and both average amplitudes tested $(\sim 0.7 \mathrm{~Pa}$ and $\sim 3 \mathrm{~Pa})$. We found no strong correlation between ATP and the intensity of the stimulus (Pearson $R^{2}=0.43$; Figure 4A). Moreover, the number of TRAP-positive multinucleated osteoclasts has a strong linear correlation to the stimulus intensity (Pearson $R^{2}=0.66$; Figure 4B).

\section{4 | Low amplitude flow regimes enhance Piezo1 and SERCA2 levels}

Understanding now that a combination of the length of loading duration per cycle and loading amplitude highly influenced the direction and magnitude of the mechanoresponse of hematopoietic progenitor cells, it remains elusive how these cells distinguish between osteoprotective and osteodestructive loading regimes. We noticed that the level of Piezo1 staining seems to be higher when osteoprotective stimuli are present compared to no mechanical stimulus. These observations led us to look further into the regulation of this mechanoreceptor. As such, we investigated the potential interaction of SERCA2 and Piezo1 after 2 minutes of mechanical loading. SERCA2, an ATPase that interacts with Piezol at the endoplasmic reticulum (ER) plasma membrane (PM) junctions, suppresses its mechanogating.

Piezo1 was visualized in hematopoietic progenitor cells subjected to a wide range of loading regimes. We confirmed our earlier observation that Piezo1 was detected with higher levels in loading regimes resulting in an osteoprotective response (Sine-LAHF, CTCF 70.633 \pm 18.202 and Square-LALF 50\%, CTCF 53.049 \pm 12.337 ) compared to loading regimes that either did not change osteoclast formation (Unloading, SquareHALF 6\%, and Square-HALF 14\%) or induced osteoclast formation (Square-HALF 50\%) (Figure 5A-C).

After 2 minutes of loading, SERCA2 was highest in loading regimes that induced an osteoprotective response (SineLAHF, CTCF $40.843 \pm 19.600$, and Square-LALF 50\%, CTCF $41.025 \pm 10.170)$. Loading regimes that either did not change osteoclast formation (Unloading, Square-HALF $6 \%$, and Square-HALF 14\%) or induced osteoclast formation (Square-HALF 22\%, Square-HALF 36\%, and Square-HALF $50 \%$ ) had very low levels of SERCA2 (Figure 5A,B,D). Linear regression analysis comparing the measured levels of SERCA2 with Piezo1 revealed a strong positive linear correlation (Pearson $R^{2}=0.63$ ) (Figure 5E).

\section{5 | Soluble factors released after mechanical loading affect osteoclast resorption area and level of CTX-I}

To investigate whether the decrease of osteoclast number in some loading regimes and the increase of osteoclast numbers 


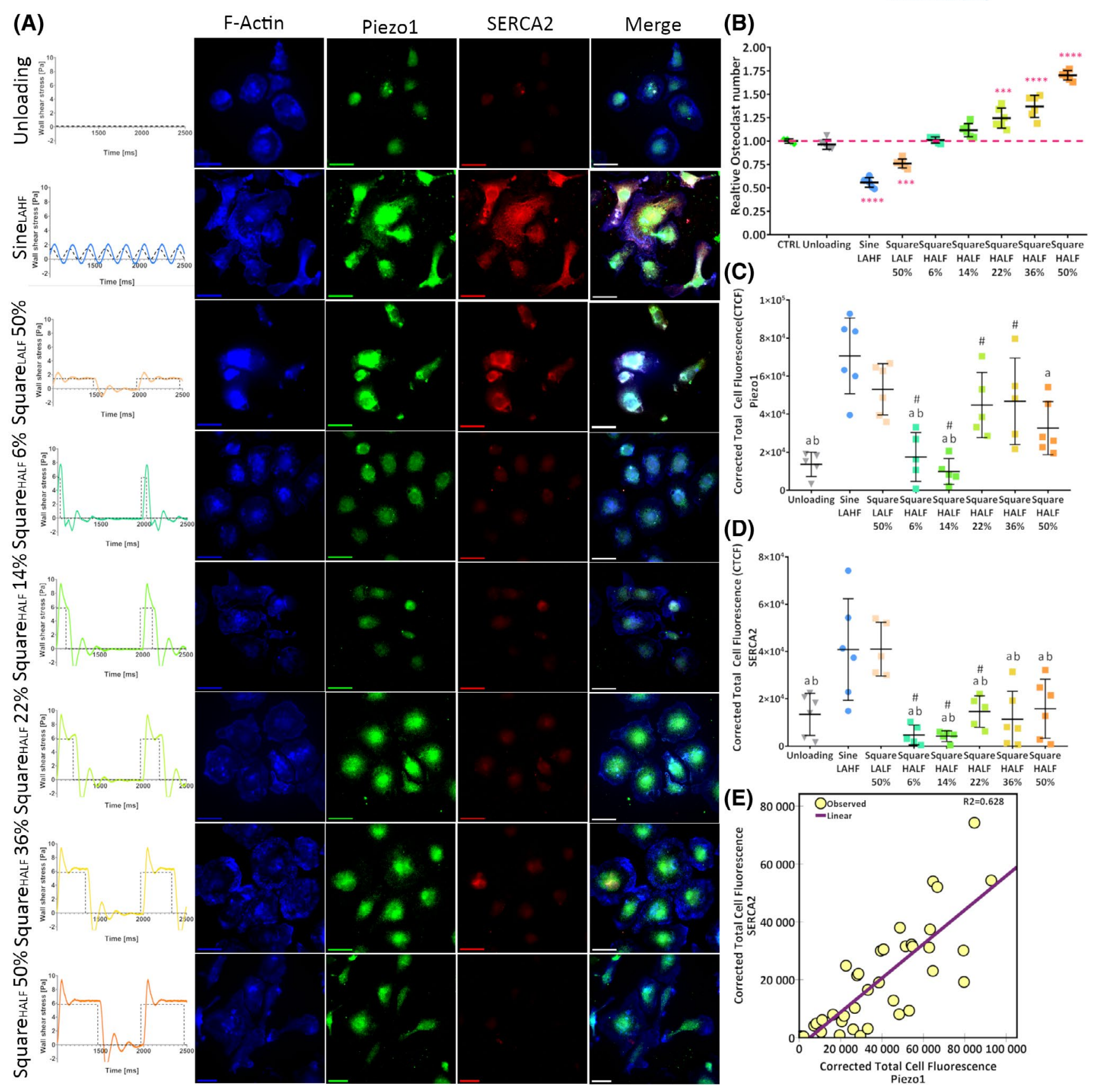

F I G U R E 5 Osteoclast-inhibiting loading regimes result in higher levels of Piezo1 and SERCA2, while osteoclast-stimulating loading regimes (Square-HALF 22\%, 36\%, and 50\%) may also increase levels of Piezo1, but not of SERCA2. Loading profiles with a variation in loading amplitude and loading duration per cycle [A] were applied for 2 minutes on hematopoietic progenitor cells. Loading profiles (Sine-LAHF and Square-LALF 50\%) that decreased osteoclast formation [B] revealed higher levels of Piezo1 [A, C] compared to unloaded cells, Square-HALF 6\%, and Square-HALF 14\%. SERCA2 [A, D] increased only in loading profiles (Sine-LAHF and Square-LALF) that decreased osteoclast formation. Correlation analysis between the cellular level of Piezo1 and cellular level of SERCA2 gives a strong positive linear relationship [E]. \# indicates groups where outliers (higher or lower than mean $\pm 2 x \mathrm{xD}$ ) were removed. $\mathrm{a}=$ statistical significance to Sine-LAHF. $\mathrm{b}=$ statistical significance to Square-LALF 50\%. Pink* = statistical significance to osteoclast assay positive control (CTRL), $* * * P<.001$, ****P<.001, one-way analysis of variance with Bonferroni post hoc test. $n=6$, separate experiments. Scale bars: $25 \mu \mathrm{m}$

in other loading regimes, reflects cells capable of resorption, we quantified the area of resorption of bovine bone slices and measured CTX-I.
The area of resorbed bone was significantly lower in loading regimes that reduced osteoclast number (Sine-LAHF, $0.67 \pm$-fold, and Square-LALF 50\%, 0.66-fold), compared to 


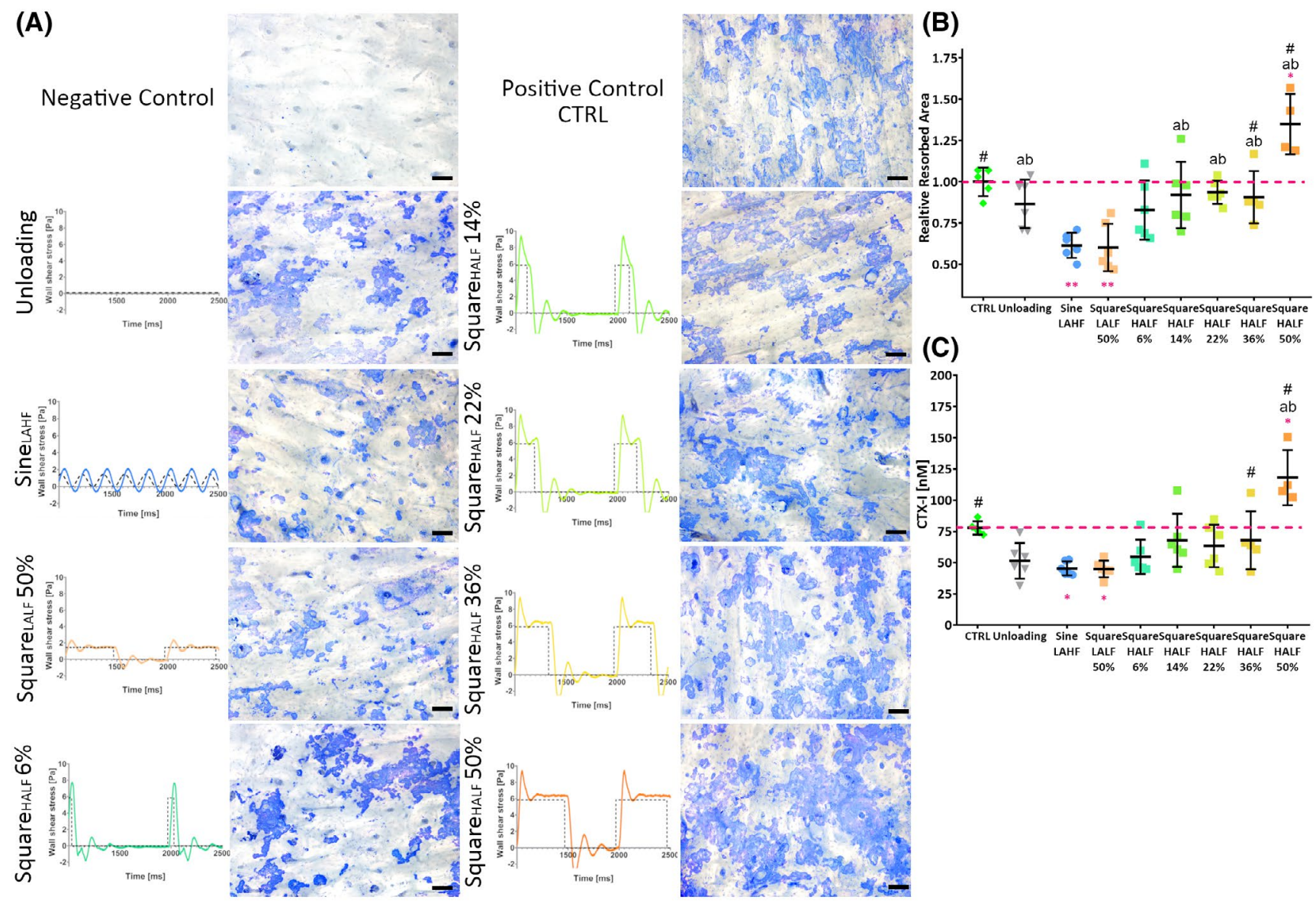

F I G U RE 6 Soluble factors released after 2 minutes of mechanical loading that modulate osteoclast formation affects resorption area and CTX-I levels. Loading profiles with a variation in loading amplitude and loading duration per cycle [A] affected the area of resorbed bone by osteoclasts. Sine-LAHF and Square-LALF 50\% reduced resorbed area on bovine bone slides compared to assay positive control and compared to all remaining loading profiles, except for Square-HALF 6\%. The loading regime that had highest number in osteoclasts formation (Square-HALF $50 \%$ ) also had highest amount of resorbed area on bovine bone slides [A, B]. The levels of soluble CTX-I were lower in both Sine-LAHF and Square-LALF 50\% compared to the control, while the loading profile that increased osteoclast number the strongest (Square-LALF 50\%) increased levels of CTX-I [C]. Please note: For improved visualization the Hue-saturation of the blue channel was enhanced by $100 \%$ for all images. \# indicate groups where repetition had to be excluded due to ill-prepared bone slices (improper sonication). a = statistical significance to SineLAHF. $\mathrm{b}=$ statistical significance to Square-LALF 50\%. Pink $*$ statistical significance to assay positive control (CTRL), $* P<.05, * * P<.01$, one-way analysis of variance with Bonferroni post hoc test. $n=6$, separate experiments. Scale bars: $100 \mu \mathrm{m}$

the assay positive control (CTRL, resorbed area $28.4 \pm 1.9 \%$ ). The loading regime that induced the most osteoclast formation (Square-HALF 50\%, 1.35-fold) increased the area of resorbed bone compared to the assay positive control. Compared to the assay positive control, the remaining loading profiles did not change osteoclast resorption. (Figure 6A,B).

Resorption was further quantified by evaluating the levels of CTX-I from the bovine bone slices. In loading regimes that reduced osteoclast number, the levels of CTX-I were lower (Sine-LAHF, 0.58-fold, and Square-LALF 50\%, 0.58 -fold) compared to the assay positive control (CTX-I $77.8 \pm 4.9 \mathrm{nM}$ ). The loading regime that inducted osteoclast formation the strongest (Square-HALF 50\%, 1.52-fold) also increased levels of CTX-I compared to the assay positive control. (Figure 6C).

\section{DISCUSSION}

Although mechanical loading from daily activity induces bone formation, clinical, and experimental evidence reveal that mechanical overloading also induces bone loss. It remains elusive what mechanical stimuli results in an osteoprotective or an osteodestructive response. The current study elucidates how fluid flow-derived mechanical stimuli affect hematopoietic progenitor cells to either enhance or suppress osteoclast formation. Specifically, we wanted to distinguish between the response to (i) peak wall shear stress rate (PWSSR), (ii) wall shear stress amplitude, (iii) duration of wall shear stress stimuli per cycle, and (iv) a surrogate for stimulus intensity defined as the product of (ii) and (iii). In addition, this study attempted to shed light on how different 
stimuli (i-iv) affect hematopoietic progenitor cells at the molecular level, focusing on the mechanoreceptor Piezo1 and the $\mathrm{Ca}^{2+}$ ATPase SERCA2. Understanding how bone cells differentiate between mechanical loading that induces osteoprotective or osteodestructive signaling cascade will provide crucial knowledge that can be used to prevent or decelerate bone degradation and thus implant loosening in orthopedic and dental applications.

Numerous studies have addressed the problem by attempting to isolate the "one" mechanical stimulus that affects mechanoresponsive bone cells. In line with these discussions, previous studies have reported that mechanoresponsive bone cells are influenced by the initial fluid displacement defined by the peak wall shear stress rate. Osteoblast-like MC3T3-E1 cells stimulated by fluid flow shear stress responded significantly to an initial rapid rate of change of shear stress (stress-kick) induced by an increased release of nitric oxide (NO), where the amount of $\mathrm{NO}$ depends on the peak wall shear stress rate. ${ }^{9}$ An animal model of osteolysis found that osteoclast formation and bone resorption due to initial fluid displacement is caused by impact loading, resulting in a sharp spike-like loading with high peak wall shear stress rate. ${ }^{8}$ These observations suggest that the initial peak wall shear stress rate is clinically relevant to how bone cells respond to fluid flow-induced mechanical loading. However, we found that in hematopoietic progenitor cells the peak wall shear stress rate seems to play only a minor role, if any, in the observed mechanical loadinginduced response. Neither Piezo1 levels nor extracellular ATP nor the osteoclast-modulating effect of released soluble factors could be strongly linked to different peak wall shear stress rates. Instead, loading amplitude and loading duration per cycle potentially offer a better explanation of modulation of osteoclast formation.

Loading amplitude is a highly discussed issue in the bone field. Early studies on turkey ulnar revealed the importance of loading frequency and rate on bone adaptation. ${ }^{25}$ Since these studies, several others have investigated the anabolic effects of either high amplitude-low frequency, or low amplitude-high frequency mechanical stimuli on bone mineral density, ${ }^{26,27}$ osteoporosis prevention, ${ }^{28}$ and fracture healing. ${ }^{29}$ Low amplitude-high frequency loading has beneficial effects on bone-implant osseointegration. ${ }^{30}$ Moreover, few studies have investigated loading duration by focusing on the active loading per cycle with a constant loading repetition and duration of loading. In hematopoietic progenitor cells, low amplitude loading was associated with an osteoprotective response that resulted in a decreased osteoclast number, resorbed bone area, and CTX-I levels, whereas high amplitude loading was associated with an osteodestructive response and increased osteoclast number. The osteodestructive loading profile with the highest number of osteoclast formation also increased resorbed area and CTX-I levels. Loading duration seems to have a tremendous influence on osteoclast formation at a constant high loading amplitude. However, the opposite could be seen at low amplitude where a decrease in osteoclast formation and resorption activity was demonstrated. A similar response has been seen in terms of the release of extracellular ATP. At a low amplitude loading, lower concentration of extracellular ATP was measured compared to a high loading amplitude. Equally, at a high amplitude, a prolonged loading duration per cycle resulted in a higher concentration of extracellular ATP compared to a shorter loading duration per cycle. Thus, the overall loading intensity seems to regulate the release of ATP. However, using the applied loading amplitude or loading duration as solitary factors to explain the observed modulation of osteoclasts, or release of ATP, might lead to a wrong interpretation since some of the osteoprotective flow regimes increase ATP release, while reducing osteoclast number. ATP release and osteoclast formation are thus not linearly correlated over the entire range of possible mechanical stimuli.

Therefore, we used a combination of loading amplitude and loading duration per cycle to describe the response of hematopoietic progenitor cells. This approach is supported by studies of red blood cells where shear stress-induced cellular deformation has been reported to depend on a combination of loading amplitude and duration. ${ }^{31}$ Furthermore, the application of strain in cell stretching devices ${ }^{32,33}$ provided strong evidence that several deformation signals highly influence the cellular response to mechanical strain. This was summarized in a mathematical expression, where amplitude, frequency, duty cycle (loading duration, duration of resting phase), number of cycles, wall shear stress rate, wall shear stress, and substrate stiffness were discussed as potential critical factors for strain-induced responses on cells. ${ }^{34}$ Although in these early observations the number of suggested contributing factors was quite large, we were able to formulate a simpler mathematical expression to describe the cellular response to a relatively wide range of fluid shear stresses, including loading amplitude and duty cycle. When applying the approximate area under the curve for square functions and error functions as a compound factor for loading amplitude and duration to explain the modulation of osteoclast formation, a strong correlation could be seen, suggesting that it is the combination of those two parameters that determine the directionality and strength of the osteoclast-modulating response. We could further eliminate that wall shear stress rate is a contributing factor to loading-induced osteoclast modulation in hematopoietic progenitor cells. Interestingly, the release of ATP, in contrast to the release of osteoclast-modulating soluble factors, seems to be more likely related directly to loading amplitude or duration per cycle at a given amplitude as a solitary factor. The strong correlation observed with extracellular ATP and loading amplitude or loading duration as solitary factors were diminished when 
applying the approximate area under the curve for square functions and error functions.

The mechanical response of a cell to shear stress is to deform or stretch. If the deformation is reversible immediately upon the cessation of loading and independent of the loading duration, the cell deforms as a perfectly elastic body, analogous to a spring. Our results indicate that the cell deformation is reversible since we were unable to detect any changes in the cell area, cell perimeter, or cell feret's diameter after loading. Furthermore, our results established that the magnitude of the mechanically induced osteo-catabolic response of the cells depends on the loading duration for a given amplitude. If we assume that this biochemical response reflects the mechanical response in the form of cell deformation, we can further hypothesize that the deformation of the cell depends on the loading duration. Hence the cells do not deform as perfect elastic bodies, but rather as viscoelastic bodies, for which deformation is dynamic under constant stress. The biomechanical description of material can take the form of a constitutive law, which gives the relationship between the local stress and the resulting local deformation or stretches. An example of a viscoelastic constitutive law is the standard linear solid model, visualized by its Kelvin (Figure 7), in the form of a Hookean spring with elastic modulus E1 coupled in series to another Hookean spring with elastic modulus E2 coupled in parallel to a viscous damper with a viscosity $\eta$. As the cell starts to experience stress, the response is an immediate elastic deformation characterized by $\mathrm{E}$ 1, followed by additional dynamic viscoelastic deformation determined by $\mathrm{E} 2$ and $\eta$.

In naïve tissue, cells with viscoelastic properties can respond either directly due to external mechanical forces or indirectly through their surrounding extracellular matrix. Cells have a variety of possibilities to detect external mechanical forces and respond accordingly.

One such mechanism is the mechanical loading-induced deformation of the cytoskeletal network, which changes the tension of the cellular membrane ${ }^{35}$ and increases the poroelasticity in the cytoplasm. ${ }^{36}$ Actin filaments, microtubules, and intermediate filaments form an adjustable network that can resist deformation, protecting the intracellular compartments. ${ }^{37}$ This

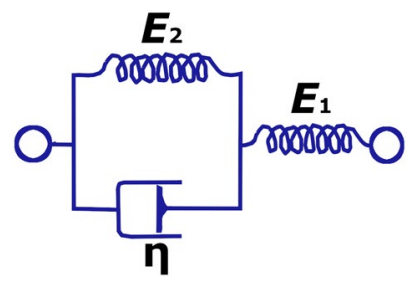

F I G U RE 7 The standard linear model in Kelvin representation. A Hookean spring with elastic modulus E1 coupled in series to another Hookean spring with elastic modulus E2 coupled in parallel to a viscous damper with a viscosity $\eta$ resistance results in a stiffening of the cytoskeletal network due to fiber elongation, fiber bending, or shorter cross-linking of the actin filaments, causing an increased elastic modulus ${ }^{38,39}$ and poroelasticity. In addition to stiffening, fluid shear stress (at approximately $1.5 \mathrm{~Pa}$ ) induces the alignment of actin filaments in cells in the fluid flow direction. ${ }^{40}$ The remodeling of the cytoskeleton and alignment of the actin filaments are results of shear stress-induced activation of signaling pathways. ${ }^{41,42}$ The cytoskeleton acts as a physical coupling mechanism to transduce external forces from the extracellular matrix directly to the outer nuclear membrane within milliseconds. ${ }^{43}$ However, loadinginduced gene expression in bone persists hours after a loading episode, ${ }^{44}$ potentially due to shear stress-induced cytoskeletal rearrangement and subsequent transduction of the signal to the nucleus, inducing changes in gene expression. However, we demonstrated a response by hematopoietic progenitor cells to mechanical loading after only 2 minutes, making the involvement of cytoskeletal rearrangements and resulting changes in gene expression questionable. Nevertheless, the observed viscoelastic deformation of cells might still depend in part on the cytoskeleton. Cytoskeletal changes in chondrocytes, osteoblasts, adipocytes, as well as breast cancer cells directly affect cellular viscoelasticity. ${ }^{45-47}$ As in our study, earlier studies have found that the viscoelastic deformation of cells increases with the applied loading amplitude and cyclic loading duration. ${ }^{48,49}$

The lipid bilayer of the plasma membrane is also known to have viscoelasticity properties, ${ }^{50}$ which influence lipid-protein or protein-protein interaction-induced cell signaling at the membrane surface. ${ }^{51}$ The mechanical properties of the lipid bilayer can change under tension, ${ }^{52}$ which affects mechanosensitive channels. ${ }^{53}$ These membrane-mediated mechanical sensors can experience shear stress-induced changes that, for example, expose cryptic binding sites, increase ion conductivity, produce conformational changes of membrane proteins, and increase tension in the lipid bilayer. ${ }^{54}$ Membrane tension highly regulates Piezo1, a cytoskeleton-independent $\mathrm{Ca}^{2+}$-permeable nonselective cation channel, ${ }^{55,56}$ which response to mechanical loading ${ }^{57}$ within milliseconds. ${ }^{18}$ Furthermore, Piezo1 is known to regulate the mechanotransductive release of ATP into the extracellular environment. ${ }^{16,17}$ Piezo1 possesses a self-regulatory gating mechanism at the globular C-terminal extracellular domain, which is crucial for frequency filtering of repetitive mechanical stimuli ${ }^{58}$ and loading intensity. ${ }^{59}$ This gating mechanism of Piezo1 allows the transitions between open, closed, and inactivated stages. ${ }^{60}$ However, the mechanism of Piezo1 inactivation remains unknown. ${ }^{61}$ Our results demonstrate levels of Piezo1 did not depend on wall shear stress applied on hematopoietic progenitor cells since all loading regimes, which seem to modulate osteoclast formation, also increased levels of Piezo1. Thus, Piezo1 alone cannot explain the tipping point between osteoanabolic and catabolic stimuli at the molecular level. On the other hand, SERCA2 levels of hematopoietic progenitor cells were only higher when stimulated with low 
intensity loading regimes (osteo-protective), while SERCA2 levels were lower in high intensity loading regimes. This finding is in line with diastolic dysfunction in postinfarction heart failure where high mechanical stress in the heart is directly linked to SERCA2 down-regulation. ${ }^{62}$ Poking-induced loading leads to co-localization of SERCA2 with Piezo1, desensitizing Piezo1. ${ }^{19}$ SERCA2 is essential for maintaining $\mathrm{Ca}^{2+}$ homeostasis by transporting cytosolic $\mathrm{Ca}^{2+}$ into SR/ER $\mathrm{Ca}^{2+}$ storage. ${ }^{63}$ To store $\mathrm{Ca}^{2+}$ in the ER, ATP needs to be hydrolyzed intracellularly rather than being secreted ${ }^{64}$ the condition found in osteoprotective loading regimes. This regulatory mechanism of Piezo1 by SERCA2 could potentially be active in mechanosensitive cells to differentiate between low intensity osteoprotective and high intensity osteodestructive loading intensities. Other studies will be performed to further investigate the mechanism behind the regulatory involvement of SERCA2.

Although the focus of this study was on the mechanosensitive receptor Piezo1, it needs to be addressed that bone cells possess several mechanisms to sense and respond to mechanical loading, some of which have been directly linked to ATP release. First, primary cilia are present on a variety of different cells, including cells of the hematopoietic lineage.$^{65}$ Fluid flow stimulation in vitro deflects primary cilia on osteocytes, which causes an immediate rise in cytosolic $\mathrm{Ca}^{2+} \cdot{ }^{26,67}$ This initial rise in intracellular $\mathrm{Ca}^{2+}$ is amplified by the release of ATP and the subsequent purinergic response through P2X and $\mathrm{P} 2 \mathrm{Y}$ receptors. ${ }^{68}$ In bone, a variety of $\mathrm{P} 2 \mathrm{X}$ and $\mathrm{P} 2 \mathrm{Y}$ receptors have been identified. ${ }^{69,70}$ We have previously demonstrated the ATP-depended release of osteoclast-modulating soluble factors by murine hematopoietic progenitor cells specifically through the $\mathrm{P} 2 \mathrm{X} 7$ receptor upon mechanical loading. ${ }^{20}$ However, little is known about the involvement of other sub-receptors in the family of $\mathrm{P} 2 \mathrm{X}$ and $\mathrm{P} 2 \mathrm{Y}$ receptors in the loading-induced release of osteoclast-modulation soluble factors. Another cellular structure, well known to be involved in bone responses to mechanical loading, are connexin $(\mathrm{Cx})$ channels, more specifically the (hemi)channels consisting of $\mathrm{Cx} 43$. Mechanical loading enhances the release of prostaglandin E2 (PGE2) and ATP through connexin hemichannels. ${ }^{71}$ Also on cells in the hematopoietic lineage, the presence of $\mathrm{Cx} 43$ supports directly intercellular communication and strong adhesion of immune cells, such as monocytes and macrophages. ${ }^{72,73}$ Although primary cilia, P2X and P2Y receptors, and connexins undoubtedly play a role in the sensing of - and response to-mechanical loading, their role in the loading-induced release of osteoclast-modulating soluble factors still needs to be investigated.

Mechanical loosening, osteolysis, and infections are the most commonly reported reasons for loosening of an implant in orthopedic areas ${ }^{74,75}$ and dental applications. ${ }^{76}$ Using a model to investigate and isolate the underlying mechanism for micromotion-induced high-pressurized fluid flow at the bone-implant interface is crucial for developing counter measurements. In this study, we used a 2D-model to evaluate the influence of fluid shear stress on hematopoietic progenitor cells. Although one might point out that using a 2D-model instead of a more complex 3D-model is a limitation in this study, we argue otherwise. The periprosthetic interface membrane is a very thin layer $(20-40 \mu \mathrm{m})^{77}$ formed between the bone and the implant and defines the area where the implant becomes loose. This thickness resembles the parallel flow chamber used in our in-vitro model for bone implant loosening and thus a 2D-model appears more clinically relevant than a 3D-model. In addition, the most dominant cell population found in this periprosthetic interface membrane are fibroblasts and macrophages. ${ }^{78}$ Therefore, the cell population chosen for this study is highly clinically relevant as we include a mixed population of monocytes, megakaryocytes, and macrophages. ${ }^{5}$ In addition to macrophages, monocytes play a crucial role in the osseointegration of bone implants. Monocytes support the recruitment and attachment of mesenchymal stromal cells onto the implant surface, which promotes osseointegration. ${ }^{79-81}$ However, a disturbing mechanical environment due to micromotions by the loosening implant at the periprosthetic interface might interfere with the attachment of mesenchymal stromal cells, further advancing the loosening process.

A variety of studies have attempted to understand how mechanical loading affects bone cells. Although it was initially thought that peak wall shear stress rate coupled with initial fluid displacement regulates osteoclast formation, our results suggest otherwise. The mechanical factor driving the response of hematopoietic progenitors is a combination of high amplitude and long-duration loading, consistent with a viscoelastic response of the cells. Our current study might signify a new ground for understanding of how mechanosensitive cells induce either an osteoprotective or an osteodestructive response, critical information for delaying or stopping implant loosening in orthopedic and dental medicine.

\section{ACKNOWLEDGMENTS}

The authors wish to thank Prof. Dr. Emeritus Per Aspenberg for his involvement in discussions and advice. The authors wish to thank Prof. Nathaniel D. Robinson from the Department of Physics, Chemistry and Biology (IFM) at Linköping University for the discussion and support during the implementation of the Error function in our in-vitro model for bone implant loosening. The authors wish to thank Senior Lecturer in Biostatistics, Mats Fredrikson, from the Department of Clinical and Experimental Medicine (IKE) at Linköping University for the support with the statistical analysis. The authors wish to thank Kathrina Radl for her involvement in discussions and practical contributions to this project during her internship at Linköping University. 


\section{CONFLICT OF INTEREST}

The authors declare that there is no conflict of interest regarding the publication of this article.

\section{AUTHOR CONTRIBUTIONS}

Designed research: C. Bratengeier, A.D. Bakker, A. Fahlgren Performed research: C. Bratengeier, A. Liszka

Data analysis and interpretation: C. Bratengeier, J. Hoffman, A.D. Bakker, A. Fahlgren

Wrote the paper: C. Bratengeier, J. Hoffman, A.D. Bakker, A. Fahlgren

\section{REFERENCES}

1. Karrholm J, Borssen B, Lowenhielm G, Snorrason F. Does early micromotion of femoral stem prostheses matter? 4-7-year stereoradiographic follow-up of 84 cemented prostheses. J Bone Joint Surg Br. 1994;76:912-917.

2. Bartlett GE, Gill HS, Murray DW, Beard DJ. In vitro influence of stem surface finish and mantle conformity on pressure generation in cemented hip arthroplasty. Acta Orthop. 2009;80:139-143.

3. Skripitz R, Aspenberg P. Pressure-induced periprosthetic osteolysis: a rat model. J Orthop Res. 2000;18:481-484.

4. Nilsson KG, Karrholm J. RSA in the assessment of aseptic loosening. J Bone Joint Surg Br. 1996;78:1-3.

5. Morse A, McDonald MM, Kelly NH, et al. Mechanical load increases in bone formation via a sclerostin-independent pathway. J Bone Miner Res. 2014;29:2456-2467.

6. Hsieh YF, Turner CH. Effects of loading frequency on mechanically induced bone formation. J Bone Miner Res. 2001;16: 918-924.

7. Mann KA, Miller MA. Fluid-structure interactions in microinterlocked regions of the cement-bone interface. Comput Methods Biomech Biomed Eng. 2014;17:1809-1820.

8. Fahlgren A, Bostrom MP, Yang X, et al. Fluid pressure and flow as a cause of bone resorption. Acta Orthop. 2010;81:508-516.

9. Bacabac RG, Smit TH, Mullender MG, Dijcks SJ, Van Loon JJ, Klein-Nulend J. Nitric oxide production by bone cells is fluid shear stress rate dependent. Biochem Biophys Res Commun. 2004;315:823-829.

10. Bacabac RG, Smit TH, Mullender MG, Van Loon JJ, KleinNulend J. Initial stress-kick is required for fluid shear stressinduced rate dependent activation of bone cells. Ann Biomed Eng. 2005;33:104-110.

11. Chow JW, Fox SW, Lean JM, Chambers TJ. Role of nitric oxide and prostaglandins in mechanically induced bone formation. J Bone Miner Res. 1998;13:1039-1044.

12. Bratengeier C, Bakker AD, Fahlgren A. Mechanical loading releases osteoclastogenesis-modulating factors through stimulation of the P2X7 receptor in hematopoietic progenitor cells. $J$ Cell Physiol. 2019;234:13057-13067.

13. Fahlgren A, Bratengeier C, Semeins CM, Klein-Nulend J, Bakker AD. Supraphysiological loading induces osteocyte-mediated osteoclastogenesis in a novel in vitro model for bone implant loosening. J Orthop Res. 2018;36:1425-1434.

14. Maneshi MM, Sachs F, Hua SZ. Heterogeneous cytoskeletal force distribution delineates the onset $\mathrm{Ca}(2+)$ influx under fluid shear stress in astrocytes. Front Cell Neurosci. 2018;12:69.
15. Gottlieb PA, Bae C, Sachs F. Gating the mechanical channel Piezo1 A comparison between whole-cell and patch recording. Channels. 2012;6:282-289.

16. Cinar E, Zhou S, DeCourcey J, Wang Y, Waugh RE, Wan J. Piezo1 regulates mechanotransductive release of ATP from human RBCs. Proc Natl Acad Sci USA. 2015;112:11783-11788.

17. Miyamoto T, Mochizuki T, Nakagomi H, et al. Functional role for Piezol in stretch-evoked $\mathrm{Ca}(2)(+)$ influx and ATP release in urothelial cell cultures. J Biol Chem. 2014;289:16565-16575.

18. Wang YB, Xiao BL. The mechanosensitive Piezo1 channel: structural features and molecular bases underlying its ion permeation and mechanotransduction. J Physiol-London. 2018;596:969-978.

19. Zhang T, Chi S, Jiang F, Zhao Q, Xiao B. A protein interaction mechanism for suppressing the mechanosensitive Piezo channels. Nat Commun. 2017;8:1797.

20. Bratengeier C, Bakker AD, Fahlgren A. Mechanical loading releases osteoclastogenesis-modulating factors through stimulation of the P2X7 receptor in hematopoietic progenitor cells. J Cell Physiol. 2019;234:13057-13067.

21. Klein-Nulend J, Semeins CM, Ajubi NE, Nijweide PJ, Burger EH. Pulsating fluid flow increases nitric oxide (NO) synthesis by osteocytes but not periosteal fibroblasts-correlation with prostaglandin upregulation. Biochem Biophys Res Commun. 1995;217:640-648.

22. Watanabe N, Kataoka H, Yasuda T, Takatani S. Dynamic deformation and recovery response of red blood cells to a cyclically reversing shear flow: effects of frequency of cyclically reversing shear flow and shear stress level. Biophys J. 2006;91:1984-1998.

23. Schindelin J, Arganda-Carreras I, Frise E, et al. Fiji: an opensource platform for biological-image analysis. Nat Methods. 2012;9:676-682.

24. McCloy RA, Rogers S, Caldon CE, Lorca T, Castro A, Burgess A. Partial inhibition of Cdk1 in G 2 phase overrides the SAC and decouples mitotic events. Cell Cycle. 2014;13:1400-1412.

25. Rubin CT, McLeod KJ. Promotion of bony ingrowth by frequency-specific, low-amplitude mechanical strain. Clin Orthop Relat Res. 1994;165-174.

26. Vainionpaa A, Korpelainen R, Vihriala E, Rinta-Paavola A, Leppaluoto J, Jamsa T. Intensity of exercise is associated with bone density change in premenopausal women. Osteoporos Int. 2006; 17:455-463.

27. Nagaraja MP, Jo H. The role of mechanical stimulation in recovery of bone loss-high versus low magnitude and frequency of force. Life (Basel). 2014;4:117-130.

28. Vanleene M, Shefelbine SJ. Therapeutic impact of low amplitude high frequency whole body vibrations on the osteogenesis imperfecta mouse bone. Bone. 2013;53:507-514

29. Rajaei Jafarabadi M, Rouhi G, Kaka G, Sadraie SH, Arum J. The effects of photobiomodulation and low-amplitude high-frequency vibration on bone healing process: a comparative study. Lasers Med Sci. 2016;31:1827-1836.

30. Shibamoto A, Ogawa T, Duyck J, Vandamme K, Naert I, Sasaki K. Effect of high-frequency loading and parathyroid hormone administration on peri-implant bone healing and osseointegration. Int $J$ Oral Sci. 2018;10:6.

31. Qiang Y, Liu J, Yang F, Dieujuste D, Du E. Modeling erythrocyte electrodeformation in response to amplitude modulated electric waveforms. Sci Rep. 2018;8:10224. 
32. Banes AJ, Link GW Jr., Gilbert JW, Tran Son Tay R, Monbureau O. Culturing cells in a mechanically active environment. Am Biotechnol Lab. 1990;8:12-22.

33. Frangos JA. Physical forces and the mammalian cell. San Diego: Academic Press; 1993.

34. Wall M, Butler D, El Haj A, Bodle JC, Loboa EG, Banes AJ. Key developments that impacted the field of mechanobiology and mechanotransduction. J Orthop Res. 2018;36:605-619.

35. White CR, Frangos JA. The shear stress of it all: the cell membrane and mechanochemical transduction. Philos Trans $R$ Soc Lond B Biol Sci. 2007;362:1459-1467.

36. Moeendarbary E, Valon L, Fritzsche M, et al. The cytoplasm of living cells behaves as a poroelastic material. Nat Mater. 2013;12:253-261.

37. Fletcher DA, Mullins RD. Cell mechanics and the cytoskeleton. Nature. 2010;463:485-492.

38. Gardel ML, Shin JH, MacKintosh FC, Mahadevan L, Matsudaira P, Weitz DA. Elastic behavior of cross-linked and bundled actin networks. Science. 2004;304:1301-1305.

39. Wagner B, Tharmann R, Haase I, Fischer M, Bausch AR. Cytoskeletal polymer networks: the molecular structure of crosslinkers determines macroscopic properties. Proc Natl Acad Sci USA. 2006;103:13974-13978.

40. van der Meer AD, Poot AA, Feijen J, Vermes I. Analyzing shear stress-induced alignment of actin filaments in endothelial cells with a microfluidic assay. Biomicrofluidics. 2010;4:11103.

41. Morales-Ruiz M, Fulton D, Sowa G, et al. Vascular endothelial growth factor-stimulated actin reorganization and migration of endothelial cells is regulated via the serine/threonine kinase Akt. Circ Res. 2000;86:892-896.

42. Wojciak-Stothard B, Ridley AJ. Shear stress-induced endothelial cell polarization is mediated by Rho and Rac but not Cdc42 or PI 3-kinases. J Cell Biol. 2003;161:429-439.

43. Kumar A, Shivashankar GV. Dynamic interaction between actin and nesprin2 maintain the cell nucleus in a prestressed state. Methods Appl Fluoresc. 2016;4:044008.

44. Mantila Roosa SM, Liu Y, Turner CH. Gene expression patterns in bone following mechanical loading. J Bone Miner Res. 2011;26:100-112.

45. Trickey WR, Vail TP, Guilak F. The role of the cytoskeleton in the viscoelastic properties of human articular chondrocytes. J Orthop Res. 2004;22:131-139.

46. Darling EM, Topel M, Zauscher S, Vail TP, Guilak F. Viscoelastic properties of human mesenchymally-derived stem cells and primary osteoblasts, chondrocytes, and adipocytes. J Biomech. 2008;41:454-464.

47. Hu J, Zhou Y, Obayemi JD, Du J, Soboyejo WO. An investigation of the viscoelastic properties and the actin cytoskeletal structure of triple negative breast cancer cells. J Mech Behav Biomed Mater. 2018;86:1-13.

48. Kim T, Hwang W, Lee H, Kamm RD. Computational analysis of viscoelastic properties of crosslinked actin networks. Plos Comput Biol. 2009;5:e1000439.

49. Hatami J, Tafazzoli-Shadpour M, Haghighipour N, Shokrgozar MA, Janmaleki M. Influence of cyclic stretch on mechanical properties of endothelial cells. Exp Mech. 2013;53:1291-1298.

50. Tamai N, Kakibe S, Tanaka S, Goto M, Matsuki H. An attempt to reveal viscoelastic behavior of lipid bilayer membrane by pressure perturbation calorimetry. High Pressure Res. 2013;33:271-277.
51. Groves JT, Kuriyan J. Molecular mechanisms in signal transduction at the membrane. Nat Struct Mol Biol. 2010;17:659-665.

52. Uline MJ, Schick M, Szleifer I. Phase behavior of lipid bilayers under tension. Biophys J . 2012;102:517-522.

53. Balleza D. Mechanical properties of lipid bilayers and regulation of mechanosensitive function from biological to biomimetic channels. Channels. 2012;6:220-233.

54. Lim CG, Jang J, Kim C. Cellular machinery for sensing mechanical force. BMB Rep. 2018;51:623-629.

55. Cox CD, Bae C, Ziegler L, et al. Removal of the mechanoprotective influence of the cytoskeleton reveals PIEZO1 is gated by bilayer tension. Nat Commun. 2016;7:10366.

56. Lewis AH, Grandl J. Mechanical sensitivity of Piezo1 ion channels can be tuned by cellular membrane tension. Elife. 2015;4:e12088.

57. Teng J, Loukin S, Anishkin A, Kung C. The force-from-lipid (FFL) principle of mechanosensitivity, at large and in elements. Pflugers Arch. 2015;467:27-37.

58. Wu J, Young M, Lewis AH, Martfeld AN, Kalmeta B, Grandl J. Inactivation of mechanically activated Piezo1 ion channels is determined by the C-terminal extracellular domain and the inner pore helix. Cell Rep. 2017;21:2357-2366.

59. Lee W, Leddy HA, Chen Y, et al. Synergy between Piezo1 and Piezo2 channels confers high-strain mechanosensitivity to articular cartilage. Proc Natl Acad Sci USA. 2014;111:E5114-E5122.

60. Lewis AH, Cui AF, McDonald MF, Grandl J. Transduction of repetitive mechanical stimuli by Piezo1 and Piezo2 ion channels. Cell Rep. 2017;19:2572-2585.

61. Zheng W, Sachs F. Investigating the structural dynamics of the PIEZO1 channel activation and inactivation by coarse-grained modeling. Proteins. 2017;85:2198-2208.

62. Roe AT, Ruud M, Espe EK, et al. Regional diastolic dysfunction in post-infarction heart failure: role of local mechanical load and SERCA expression. Cardiovasc Res. 2019;115:752-764.

63. Brini M, Carafoli E. Calcium pumps in health and disease. Physiol Rev. 2009;89:1341-1378.

64. Mahmmoud YA. Capsaicin stimulates uncoupled ATP hydrolysis by the sarcoplasmic reticulum calcium pump. J Biol Chem. 2008;283:21418-21426.

65. Singh M, Chaudhry P, Merchant AA. Primary cilia are present on human blood and bone marrow cells and mediate Hedgehog signaling. Exp Hematol. 2016;44(1181-1187):e1182.

66. Su S, Phua SC, DeRose R, et al. Genetically encoded calcium indicator illuminates calcium dynamics in primary cilia. Nat Methods. 2013;10:1105-1107.

67. Jin XJ, Mohieldin AM, Muntean BS, et al. Cilioplasm is a cellular compartment for calcium signaling in response to mechanical and chemical stimuli. Cell Mol Life Sci. 2014;71:2165-2178.

68. Praetorius HA. The primary cilium as sensor of fluid flow: new building blocks to the model. A review in the theme: cell signaling: proteins, pathways and mechanisms. Am J Physiol-Cell Ph. 2015;308:C198-C208.

69. Hoebertz A, Townsend-Nicholson A, Glass R, Burnstock G, Arnett TR. Expression of P2 receptors in bone and cultured bone cells. Bone. 2000;27:503-510.

70. Jorgensen NR, Adinolfi E, Orriss I, Schwarz P. Purinergic signaling in bone. J Osteoporos. 2013;2013:673684.

71. Lloyd SA, Loiselle AE, Zhang Y, Donahue HJ. Shifting paradigms on the role of connexin43 in the skeletal response to mechanical load. J Bone Miner Res. 2014;29:275-286. 
72. Navab M, Liao F, Hough GP, et al. Interaction of monocytes with cocultures of human aortic wall cells involves interleukins 1 and 6 with marked increases in connexin43 message. J Clin Invest. 1991;87:1763-1772.

73. Beyer EC, Steinberg TH. Evidence that the gap junction protein connexin-43 is the Atp-induced pore of mouse macrophages. J Biol Chem. 1991;266:7971-7974.

74. Gwam CU, Mistry JB, Mohamed NS, et al. Current epidemiology of revision total hip arthroplasty in the United States: national inpatient sample 2009 to 2013. J Arthroplasty. 2017;32:2088-2092.

75. Delaunay C, Hamadouche M, Girard J, Duhamel A, Grp S. What are the causes for failures of primary hip arthroplasties in France? Clin Orthop Relat R. 2013;471:3863-3869.

76. Fretwurst T, Nelson K, Tarnow DP, Wang HL, Giannobile WV. Is metal particle release associated with peri-implant bone destruction? an emerging concept. J Dent Res. 2018;97:259-265.

77. Wechalekar MD, Smith MD. Utility of arthroscopic guided synovial biopsy in understanding synovial tissue pathology in health and disease states. World J Orthop. 2014;5:566-573.

78. Goldring SR, Schiller AL, Roelke M, Rourke CM, O'Neil DA, Harris WH. The synovial-like membrane at the bone-cement interface in loose total hip replacements and its proposed role in bone lysis. J Bone Joint Surg Am. 1983;65:575-584.

79. Lenneras M, Ekstrom K, Vazirisani F, et al. Interactions between monocytes, mesenchymal stem cells, and implants evaluated using flow cytometry and gene expression. J Tissue Eng Regen M. 2018;12:1728-1741.

80. Ekstrom K, Omar O, Graneli C, Wang XQ, Vazirisani F, Thomsen P. Monocyte exosomes stimulate the osteogenic gene expression of mesenchymal stem cells. Plos One. 2013;8:e75227.

81. Gamblin AL, Brennan MA, Renaud A, et al. Bone tissue formation with human mesenchymal stem cells and biphasic calcium phosphate ceramics: The local implication of osteoclasts and macrophages. Biomaterials. 2014;35:9660-9667.

\section{SUPPORTING INFORMATION}

Additional supporting information may be found online in the Supporting Information section.

How to cite this article: Bratengeier C, Liszka A, Hoffman J, Bakker AD, Fahlgren A. High shear stress amplitude in combination with prolonged stimulus duration determine induction of osteoclast formation by hematopoietic progenitor cells.

The FASEB Journal. 2020;34:3755-3772. https://doi.org/10.1096/fj.201901458R 